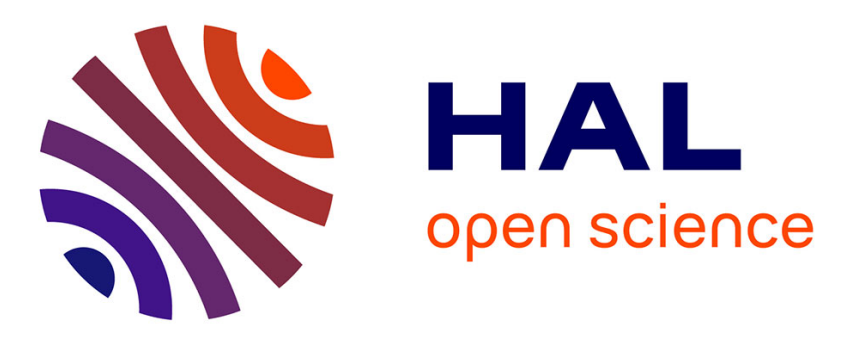

\title{
Inclusion of a Third Soil Layer in a Land Surface Scheme Using the Force-Restore Method
}

\author{
Aaron Anthony Boone, Jean-Christophe Calvet, Joël Noilhan
}

\section{To cite this version:}

Aaron Anthony Boone, Jean-Christophe Calvet, Joël Noilhan. Inclusion of a Third Soil Layer in a Land Surface Scheme Using the Force-Restore Method. Journal of Applied Meteorology, 1999, 38 (11), pp.1611-1630. 10.1175/1520-0450(1999)0382.0.CO;2 . hal-02269589

\section{HAL Id: hal-02269589 \\ https://hal.science/hal-02269589}

Submitted on 23 Aug 2019

HAL is a multi-disciplinary open access archive for the deposit and dissemination of scientific research documents, whether they are published or not. The documents may come from teaching and research institutions in France or abroad, or from public or private research centers.
L'archive ouverte pluridisciplinaire HAL, est destinée au dépôt et à la diffusion de documents scientifiques de niveau recherche, publiés ou non, émanant des établissements d'enseignement et de recherche français ou étrangers, des laboratoires publics ou privés. 


\title{
Inclusion of a Third Soil Layer in a Land Surface Scheme Using the Force-Restore Method
}

\author{
Aaron Boone, Jean-Christophe Calvet, and Joël Noilhan \\ Météo-France/Centre National de Recherche Météorologique, Toulouse, France
}

(Manuscript received 14 April 1998, in final form 7 November 1998)

\section{ABSTRACT}

\begin{abstract}
The inclusion of a third soil layer in the Interactions between Soil, Biosphere, and Atmosphere (ISBA) model is presented in this paper. The soil water content between the base of the root zone and the deep soil layer is described using a generalized form of the force-restore method. The new force-restore coefficient is calibrated using a detailed high-resolution soil water transfer model and then is related to the soil textural properties using simple regression relationships. It is shown that the use of a calibrated coefficient gives better results, in general, than a direct solution method when using similar model geometry with the same number of layers.

In the initial two-layer version of ISBA, it was not possible to distinguish the root zone and subroot zone soil water reservoirs. With the three-layer version, the deep soil layer may provide water to the system through capillary rises only, and the available water content (for transpiration) is clearly defined. Three test cases are examined in which atmospheric forcing, a good description of the soil properties and vegetation cover, and measured soil moisture profile data are present for an annual cycle. Use of the three-layer version of ISBA gives general improvement in modeling results, and values for key parameters that relate evapotranspiration to soil moisture are more consistent with those inferred from observations, compared with the two-layer version.
\end{abstract}

\section{Introduction}

Over the past decade soil-vegetation-atmosphere transfer (SVAT) schemes have greatly improved. The link between the soil hydrology and the partitioning of incoming net radiation into sensible, ground, and latent heat fluxes was found, in particular, to be crucial within these models (Shao and Henderson-Sellers 1996). The Interactions between Soil, Biosphere, and Atmosphere (ISBA) SVAT model (Noilhan and Planton 1989; Noilhan and Mahfouf 1996) evolved to account for the increased knowledge of this linkage through the participation in the Project for the Intercomparison of Landsurface Parameterization Schemes (PILPS) (HendersonSellers et al. 1993).

The ISBA model has evolved so as to keep model complexity to a minimum while still capturing the most important physical processes in the coupled land-atmosphere system. To this end, a two-layer soil hydrological model configuration has been used. A thin upper layer acts as a reservoir for evaporation from the soil surface, and a single subsurface (or bulk) soil layer is used to model the mean water content for the root and

Corresponding author address: Dr. Aaron A. Boone, MétéoFrance, CNRM/GMME/MC2, 42 avenue Coriolis, 31057 Toulouse Cedex, France.

E-mail: boone@cnrm.meteo.fr subroot zone layers at a point or within a grid box. Recently, however, limitations to this two-layer approach have been found through participation in the Global Soil Wetness Project (GSWP) (Dirmeyer 1997). The computation of the soil water index and the partitioning of precipitation between runoff and evapotranspiration within ISBA should be improved by distinguishing between a plant root-extraction layer and a subroot zone soil layer (Douville 1997).

Many SVAT schemes (including those involved in PILPS and GSWP) use three soil layers for computing the soil water content profile: a diffusion equation is solved for a low-resolution vertical grid comprising a bare soil or surface layer, a subsurface or root zone layer, and a deep soil reservoir [e.g., Simple Biosphere model (SiB) (Sellers et al. 1986), Canadian Land Surface Scheme (CLASS) (Verseghy 1991), Biosphere-Atmosphere Transfer Scheme (BATS) (Dickinson et al. 1993), bare soil parameterization scheme (BARESOIL) (Dekić et al. 1995), Variable Infiltration Capacity Model (VIC) (Liang et al. 1996), Simplified SiB model (SSiB) (Xue et al. 1996), Land-Air Parameterization Scheme (LAPS) (Mihailovic 1996), grid square mosaic approach (Mosaic) (Koster and Suarez 1996), Best Approximation of Surface Exchanges scheme (BASE) (Desborough and Pitman 1998)], although the various methodologies or implementations vary across the schemes. The soil moisture is characterized by two variables in ISBA: a bare soil layer and a mean total soil column water con- 
tent layer (including the base soil layer). The objective of this study is to include a third soil water reservoir in ISBA by distinguishing between the root zone and a base flow layer. A Newtonian-restore approach similar to the force-restore method is used to model the vertical diffusion across these two layers. Such improvements of the original force-restore method already have been incorporated in the scheme through the inclusion of gravitational drainage (Mahfouf and Noilhan 1996, hereinafter referred to as MN96).

It is necessary to make the distinction between a root zone layer and subroot zone soil water recharge layer primarily to capture the large vertical moisture gradient that can develop between these regions during the growing season (Betts et al. 1993). As the root zone soil layer dries up, atmospheric evaporative demand partially is met through vertical diffusion of soil water from subroot zone layers. Using a single layer to lump the root zone and subroot zone layers can result in too much evapotranspiration during water-stressed conditions, as vertical diffusion from subroot zone layers implicitly is unrealistically large. In contrast, if the modeled total soil depth extends only to the base of the root zone, the lack of a vertical diffusion mechanism can result in an underestimation of total evapotranspiration. Additionally, the use of a single bulk layer can result in too little transpiration after heavy precipitation events that occur over relatively dry soils (Stamm et al. 1994). This underrepresentation results from the relatively small change in the total soil water content with precipitation events for relatively thick soil columns.

The use of distinct layers for computing the surface runoff and the base flow runoff results in greater timescale separation of the runoff components. The variational infiltration method (Wood et al. 1992) for surface runoff generation in ISBA (Habets and Noilhan 1997) produces a more rapid time response of surface runoff to precipitation or snowmelt events when it is calculated using the mean water content of the upper soil layer (as opposed to the mean total soil column value). The use of a subroot zone layer dampens the amplitude of drainage pulses and increases the time lag between infiltration and drainage, resulting in a more realistic base flow time series.

In contrast to the three-layer soil hydrological configuration, there are numerous operational and research SVAT schemes that incorporate four or more soil hydrological layers using a direct solution of the Richards equation: For example, Goddard Institute for Space Studies (GISS) (Abramopoulos et al. 1988), Parameterization for Land-Atmosphere-Cloud Exchange (PLACE) (Wetzel and Boone 1995), European Centre for Medium-Range Weather Forecasts (ECMWF) (Viterbo and Beljaars 1995), Bare Essentials of Surface Transfer (BEST) (Yang et al. 1995), Land Surface Model (LSM) (Bonan 1996), and Atmosphere-Land Surface Interaction Scheme (ALSIS) (Irannejad and Shao 1996). The soil moisture vertical gradient can be very large over the depth of the soil column, so that the most important advantages of using greater vertical resolution are a more accurate numerical solution and a more detailed representation of the soil water vertical transfer processes (such as infiltration and the wetting front). One disadvantage of such an approach compared to the force-restore method is the increased computational expense. The direct solution of the Richards equation involves the use of an implicit (possibly iterative) scheme, which is costly because of the nonlinear soil water release functions. Another reason for using a multilayer approach is the ability to model a vertical root zone distribution. But the use of a root zone distribution introduces an additional parameter that is poorly known on large spatial scales. Desborough (1997) showed that the chosen distribution has a profound effect on the resulting surface latent heat fluxes. Bulk root zone formulations are probably a better option for operational or climate-scale simulations because there is a general lack of understanding of the effects of root zone distributions on modeled surface fluxes at large spatial scales, so their usefulness is limited at the present time.

ISBA is used in the operational French weather forecast model (Giard and Bazile 2000) ARPEGE (Action de Recherche Petite Echelle-Grand Echelle) in addition to various research applications. An additional complication with respect to the use of a multilayer approach in ISBA for operational simulations is the problem of specifying the vertical distribution of the assimilated soil water content for many soil layers in a numerical weather prediction model. The main advantages of our threelayer approach are that the force-restore coefficients are calibrated using a more sophisticated model (thus, in principle, modeled vertical soil water transfers should be superior to a direct solution of the Richards equation for a three-layer model), the numerical representation is relatively straightforward so that the solution method is efficient computationally, and only a single new model parameter (rooting depth) is introduced.

The extension of a one-dimensional soil column approach to larger spatial scales (e.g., climate scale, mesoscale) introduces several issues related to subgrid heterogeneity of soil moisture and its effect on area-average evapotranspiration and runoff. This heterogeneity results mainly from subgrid variability of soil texture, topography, vegetation coverage, and precipitation. ISBA (like most SVAT schemes) is validated using point measurements of soil moisture and atmospheric fluxes, and this spatial scale is, in general, adequate for the application of Darcy's law using the soil parameters and water release functions from such popular models as Clapp and Hornberger (1978) and Cosby et al. (1984).

These models describe the relation among soil moisture, soil water potential, and hydraulic conductivity through empirical relations. However, Kabat et al. (1997) suggest that these parameters must be properly scaled up to have meaning on larger scales. Area-averaged soil textural properties were used to determine 
effective hydrological parameters in ISBA (Noilhan and Lacarrère 1995) at the mesoscale. Statistical methods also exist wherein assumed probability density distribution is applied to the point equations to account for soil moisture heterogeneity (Wetzel and Chang 1988; Entekhabi and Eagleson 1989) and the subsequent effect on evapotranspiration and runoff. Other methods use functions that depend upon topography and the gridbox average soil moisture to determine an effective fraction of the soil that is saturated in order to calculate gridaverage bare soil evaporation and subgrid surface runoff (Wood et al. 1992; Dumenil and Todoni 1992). This type of scheme is used by ISBA to estimate subgrid surface runoff for sufficiently large spatial scales (Habets and Noilhan 1997).

Note that, even by scaling the soil parameters and modeling the spatial horizontal heterogeneity of soils for large spatial scales, the one-dimensional framework used by many SVAT schemes (including ISBA) is a critical assumption that is not always physically consistent with respect to subsurface soil water transport. Although single-point validation and sensitivity studies (such as those used by PILPS and the cases used in the current study) are valuable with respect to increasing the understanding of the applicability and certain limitations of SVAT schemes, extrapolation of parameter values from such studies that use a one-dimensional modeling framework to larger spatial scales (such as those used in certain operational or climate-scale atmospheric numerical weather prediction models) must be done with this critical assumption in mind.

The addition of a third prognostic soil water variable, the method for calibrating the additional model parameters, model sensitivity to key transpiration parameters, and results from three case studies are presented in this paper.

\section{ISBA governing equations for soil moisture}

The ISBA scheme was developed at Météo-France to provide fluxes of heat, momentum, and moisture from the surface to the overlying atmosphere in numerical weather prediction models (Noilhan and Planton 1989). The scheme uses the force-restore method (Deardorff 1977) to calculate the time evolution of the surface and mean soil temperatures, the water interception storage reservoir, and two soil moisture reservoirs (surface and total soil). The ISBA model is described in detail in Noilhan and Mahfouf (1996), and additional state variables related to snow cover are described in Douville et al. (1995).

There is an additional reservoir in the three-layer version of ISBA. The governing equations for the time $(t)$ evolution of soil moisture for the three soil layers are written as

$$
\begin{aligned}
& \frac{\partial w_{g}}{\partial t}=\frac{C_{1}}{\rho_{w} d_{1}}\left(I-E_{g}\right)-D_{1}, \\
& \frac{\partial w_{2}}{\partial t}=\frac{1}{\rho_{w} d_{2}}\left(I-E_{g}-E_{\mathrm{tr}}\right)-K_{2}-D_{2},
\end{aligned}
$$

and

$$
\frac{\partial w_{3}}{\partial t}=\frac{d_{2}}{\left(d_{3}-d_{2}\right)}\left(K_{2}+D_{2}\right)-K_{3},
$$

where gravitational drainage of soil water is represented by $K\left(\mathrm{~s}^{-1}\right)$, vertical soil moisture diffusion is $D\left(\mathrm{~s}^{-1}\right)$, and $C_{1}$ is the dimensionless surface restore coefficient. The density of liquid water is $\rho_{w}\left(\mathrm{~kg} \mathrm{~m}^{-3}\right), d_{1}$ is the superficial soil depth, $d_{2}(\mathrm{~m})$ is the depth of the rooting layer, and $d_{3}(\mathrm{~m})$ is the total modeled soil depth. This depth can be considered to be where the soil moisture change with respect to time can be neglected. This information generally is determined from the observed soil moisture profile, but it is not always available; $d_{3}$ can be determined from ancillary information (such as the measured or inferred total depth of the soil) or from sensitivity tests. The ratio $d_{2} /\left(d_{3}-d_{2}\right)$ in Eq. (3) is a conversion factor needed to conserve the total column soil water when the grid thicknesses of layers two and three are different.

The layer-average volumetric water contents $\left(\mathrm{m}^{3}\right.$ $\mathrm{m}^{-3}$ ) for the surface, root zone, and deep soil layers are given by $w_{g}, w_{2}$, and $w_{3}$, respectively. The volumetric water content within each reservoir is constrained to be less than the saturation water content or porosity $w_{\text {sat }}$ $\left(\mathrm{m}^{3} \mathrm{~m}^{-3}\right)$, which is a function of soil textural properties and represents the maximum amount of water the soil can hold. The root zone layer overlaps the surface layer, whereas the deep-soil soil water reservoir extends from the base of the root zone $\left(d_{2}\right)$ to the base of the modeled soil column $\left(d_{3}\right)$. Equations (1)-(3) are integrated using an implicit time scheme to ensure numerical stability for large time steps, using a linearization method (Giordani 1993).

In Eqs. (1) and (2), bare soil evaporation and plant transpiration rates $\left(\mathrm{m} \mathrm{s}^{-1}\right)$ are represented by $E_{g}$ and $E_{\mathrm{tr}}$ (Noilhan and Mahfouf 1996), respectively. Plant transpiration continues while the root zone water content is larger than the wilting point volumetric water content. The infiltration rate $I\left(\mathrm{~m} \mathrm{~s}^{-1}\right)$ is given by

$$
I=P_{g}-R_{\mathrm{sfc}},
$$

where $P_{g}$ is the rate at which liquid water reaches the soil hydrological surface, and $R_{\text {sfc }}$ is the surface runoff that is generated when the soil moisture exceeds the soil porosity. For relatively large spatial scales (such as those scales used in mesoscale or climate modeling), surface runoff is computed using the variational infiltration method as a function of $w_{2}$ (Douville 1997; Habets and Noilhan 1997).

The drainage $(K)$ and vertical diffusion $(D)$ terms are written as 
ISBA-2L

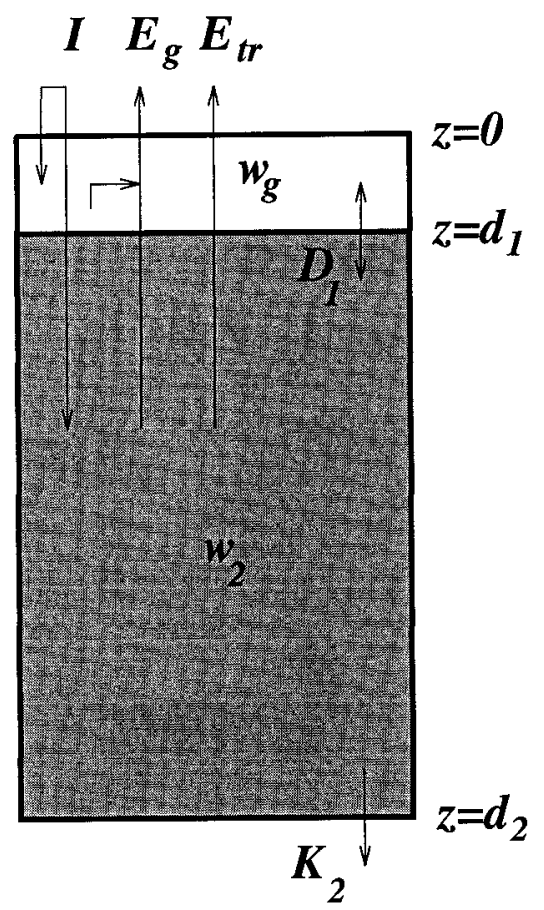

ISBA-3L

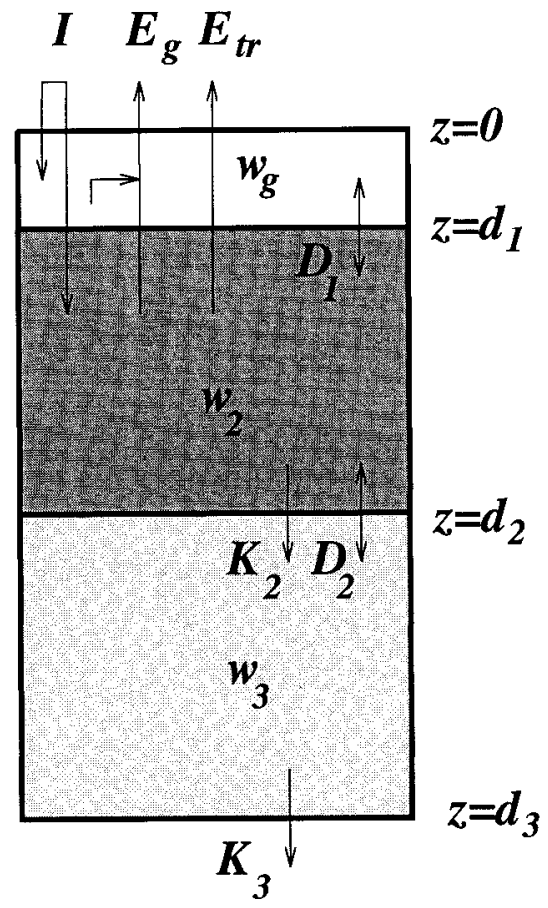

FIG. 1. The two-layer (ISBA-2L) and three-layer (ISBA-3L) soil grid configurations for ISBA. The three-layer scheme includes distinct root and subroot zone reservoirs. For the two grid geometries, the nonshaded region represents the bare soil layer, the dark-shaded region represents the layer that includes the root zone, and the light gray area (ISBA-3L) represents the subroot zone layer. Expressions for the diffusion $\left(D_{1}\right.$ and $\left.D_{2}\right)$ and gravitational drainage terms $\left(K_{2}\right.$ and $\left.K_{3}\right)$ are given by Eqs. (7)-(8) and (5)-(6), respectively. Soil depths are represented by $d$, the mean volumetric water content of each layer is given by $w$, infiltration is represented by $I$, and the bare soil evaporation and transpiration rates are denoted by $E_{g}$ and $E_{\mathrm{tr}}$, respectively.

$$
\begin{aligned}
K_{2} & =\frac{C_{3}}{\tau} \frac{d_{3}}{d_{2}} \max \left[0,\left(w_{2}-w_{\mathrm{fc}}\right)\right], \\
K_{3} & =\frac{C_{3}}{\tau} \frac{d_{3}}{\left(d_{3}-d_{2}\right)} \max \left[0,\left(w_{3}-w_{\mathrm{fc}}\right)\right], \\
D_{1} & =\frac{C_{2}}{\tau}\left(w_{g}-w_{\text {geq }}\right),
\end{aligned}
$$

and

$$
D_{2}=\frac{C_{4}}{\tau}\left(w_{2}-w_{3}\right),
$$

where $\tau(\mathrm{s})$ represents the restore constant of one day. The surface volumetric water content at the balance of gravity and capillary forces is represented by $w_{\text {geq }}$, and $w_{\mathrm{fc}}$ is the field capacity volumetric water content (both $\mathrm{m}^{3} \mathrm{~m}^{-3}$ ). The total soil water within the column is expressed simply as the grid thickness-weighted sum of $w_{2}$ and $w_{3}$. The two-layer (ISBA-2L) and three-layer (ISBA-3L) model configurations are shown in Fig. 1. The dark-shaded areas indicate the rooting depth for both model versions. The light gray-shaded area in
ISBA-3L represents the subroot zone reservoir $\left(w_{3}\right)$. The directions of the diffusion $(D)$, drainage $(K)$, infiltration $(I)$, and evapotranspiration $(E)$ fluxes are indicated by the arrows, and the soil depth $z$ is increasing downward.

The ISBA dimensionless force-restore soil hydrological parameters $C_{1}, C_{2}, C_{3}$, and $C_{4}$ and the soil hydrological parameters $w_{\text {geq }}, w_{\text {wilt }}$, and $w_{\text {fc }}$ are related to the soil texture properties and moisture (appendix A) using the parameter expressions and values from Clapp and Hornberger (1978: hereinafter referred to as $\mathrm{CH} 78$ ). These expressions relate hydraulic conductivity $k$ and soil water potential $\psi$ to volumetric soil water content as a function of soil type (Brooks and Corey 1966; CH78);

$$
\psi=\psi_{\mathrm{sat}}\left(w / w_{\mathrm{sat}}\right)^{-b}
$$

and

$$
k=k_{\mathrm{sat}}\left(w / w_{\mathrm{sat}}\right)^{2 b+3},
$$

where $k_{\text {sat }}$ is the saturated hydraulic conductivity $\left(\mathrm{m} \mathrm{s}^{-1}\right)$, $\psi_{\text {sat }}$ is the saturated soil water potential (m), and $b$ (di- 
mensionless) is the slope of the soil moisture retention curve. The wilting-point volumetric water content $w_{\text {wilt }}$ is computed for each soil class using Eq. (9a) together with the $\mathrm{CH} 78$ parameter values, assuming a critical plant potential value of $-150 \mathrm{~m}$ (MN96). The critical plant potential varies between -100 and $-300 \mathrm{~m}$ for most plant species, but the values for $w_{\text {wilt }}$ only change slightly over this range. The field capacity volumetric water content is computed from Eq. (9b), assuming a hydraulic conductivity of $0.1 \mathrm{~mm}$ day $^{-1}$ (Wetzel and Chang 1987) and using the parameter values from CH78 (Jacquemin and Noilhan 1990). The field capacity and wilting-point water contents are convenient parameters for defining various soil water quantities but they are not fundamental properties of the soil (Hillel 1971). The soil texture is used to define these parameters unless ancillary information is available (such as observed values).

The subsurface vertical diffusion $\left(D_{2}\right)$ and gravitational drainage $\left(K_{2}\right)$ root zone soil water flux components are treated as distinct processes in ISBA-3L for two reasons. First, $K_{2}$ is formulated in the same manner as $K_{3}$ so as to be consistent with drainage out of the base of the model. Second, the vertical soil moisture flux is parameterized using Darcy's law: the diffusion and drainage processes behave differently over the same range of soil moisture and are associated with very different timescales. Gravitational drainage is much larger than vertical diffusion for soil moisture values that are approaching saturation: coarse soils with a total depth of 1 or $2 \mathrm{~m}$ can drain to field capacity within a matter of a few days. On the other hand, vertical diffusion is the dominant soil water flux component at soil moisture values below field capacity. The time required for the profile to be restored to equilibrium for a soil (with a similar total depth) can be on the order of weeks, especially for fine-textured soils.

\section{Parameterization of vertical diffusion}

The calibration of the root zone force-restore coefficient $\left(C_{4}\right)$ is similar to the method used to determine the surface layer force-restore coefficient $\left(C_{2}\right)$ (Noilhan and Planton 1989). A multilayer, variable-depth, onedimensional soil moisture model (MLSM) that integrates the Richards equation while assuming a homogeneous vertical texture profile and isothermal conditions (Boone and Wetzel 1996) was run offline from ISBA to calibrate $C_{4}$. In MLSM, subsurface vertical moisture fluxes are governed by Darcy's law, and hydraulic conductivity and soil matric potential are related to the volumetric water content through the empirical relations from CH78 [Eqs. (9a) and (9b)] for this study. MLSM uses an implicit time scheme and 100 soil layers on a stretched vertical grid; high spatial resolution was used so as to obtain accurate solutions by minimizing truncation errors.

Although the same general calibration method was used, and both the $C_{2}$ and $C_{4}$ terms represent vertical soil moisture diffusion [Eqs. (7) and (8), respectively], the values for $C_{2}$ and $C_{4}$ are different. The $C_{2}$ coefficient was calibrated over a thin surface layer depth without explicit consideration of the thickness of the layer below, as the depth of the surface layer generally is much less than that of the reservoir $w_{2}$. The $C_{4}$ coefficient was calibrated by taking into account the grid geometry of both subsurface soil layers, as the thicknesses can be similar in magnitude. Also, the surface soil water content $\left(w_{g}\right)$ restores to a water content value $\left(w_{g \text { eq }}\right)$ that represents the balance of gravity and capillarity [Eq. (1)]. In general, $w_{\text {geq }}$ resembles $w_{2}$ except for coarsetextured soils. In contrast, the subsurface soil reservoirs restore to relax the subsurface soil water gradient directly [Eqs. (2) and (3)].

The MLSM model was integrated over a total soil depth ranging from 2 to $7 \mathrm{~m}$, using a stretched grid and a total of 100 model layers with the highest vertical resolution near the soil surface. The base of the root zone $\left(d_{2}\right)$ ranged from 0.1 to $3 \mathrm{~m}$ for these tests. The soil classes described in $\mathrm{CH} 78$ were used to define $b$, $k_{\text {sat }}$, and $w_{\text {sat }}$ for 11 soil textures. The mean $\psi_{\text {sat }}$ value of $-0.39 \mathrm{~m}$ (Cosby et al. 1984) was used for all soil classes as this parameter is not well correlated with soil texture (CH78; Dickinson 1984). The vertical soil water flux is written following Darcy's law as

$$
W_{s}(z)=\rho_{w} k\left(\frac{\partial \psi}{\partial z}+1\right),
$$

where $W_{s}$ is the soil water flux and $z$ is the vertical coordinate. The boundary conditions were specified such that there were no vertical or lateral soil water fluxes into or out of the model from $z=0$ to $z=d_{3}$ :

$$
W_{s}(z=0)=I=E_{g}=E_{\mathrm{tr}}=0
$$

and

$$
W_{s}\left(z=d_{3}\right)=\rho_{w}\left(\mathcal{D} \frac{\partial w}{\partial z}+k\right)=0,
$$

where the diffusion coefficient in Eq. (11b) is written as

$$
\mathcal{D}=k \partial \psi / \partial w .
$$

Substitution of Eqs. (9a) and (9b) into Eq. (12a) yields an expression for the diffusion coefficient as a function of the soil hydrological texture parameters:

$$
\mathcal{D}=\frac{-b \psi_{\mathrm{sat}} k_{\mathrm{sat}}}{w_{\mathrm{sat}}}\left(\frac{w}{w_{\mathrm{sat}}}\right)^{b+2} .
$$

\section{1) Methodology}

An estimate of the speed at which the profiles returned to equilibrium $\left(C_{4}\right)$ was obtained by doing hundreds of simulations for each soil class and various grid config- 
urations (i.e., different values of $d_{2}$ and $d_{3}$ ) using a matrix of initial $w_{2}$ and $w_{3}$ values, which then were interpolated linearly as a function of soil depth to the MLSM high-resolution grid. The initial mean water content of the profiles ranged from wilting point to field capacity, so that gravitational drainage was negligible (diffusion was the dominant soil moisture transfer mechanism) and no runoff (due to saturation) occurred. Profile-mean water content values below wilting point were not used since the total soil column moisture should rarely (if ever) drop much below wilting point, and also diffusion would become very weak at these moisture values.

By using the definition of $D_{2}$ from Eq. (8) together with the boundary conditions given by Eqs. (11a) and (11b), the prognostic equations for the subsurface soil water reservoirs [Eqs. (2) and (3), respectively] can be rewritten as

$$
\frac{\partial w_{2}}{\partial t}=-\frac{C_{4}}{\tau}\left(w_{2}-w_{3}\right)
$$

and

$$
\frac{\partial w_{3}}{\partial t}=\frac{d_{2}}{\left(d_{3}-d_{2}\right)} \frac{C_{4}}{\tau}\left(w_{2}-w_{3}\right),
$$

where drainage is negligible. Subtraction of Eq. (14) from Eq. (13) yields

$$
\frac{\partial\left(w_{2}-w_{3}\right)}{\partial t}=-\frac{d_{3}}{\left(d_{3}-d_{2}\right)} \frac{C_{4}}{\tau}\left(w_{2}-w_{3}\right) .
$$

The equation that describes the soil water gradient $\left(w_{2}\right.$ $-w_{3}$ ) at time $t$ can be found by integrating Eq. (15) to obtain

$$
\left(w_{2}-w_{3}\right)(t)=\left(w_{2}-w_{3}\right)\left(t_{0}\right) \exp \left[-\frac{C_{4} d_{3}\left(t-t_{0}\right)}{\left(d_{3}-d_{2}\right) \tau}\right],
$$

where $t_{0}$ represents the starting time for the integration. The soil water gradient that corresponds to $w_{2}-w_{3}$ was calculated from the MLSM output soil water profiles using the thickness-weighted soil water contents for $w_{2}$ for the layer extending from $z=0$ to $z=d_{2}$ and for $w_{3}$ from $z=d_{2}$ to $z=d_{3}$. When the soil water gradient relaxed to $1 / e$ of its initial value, then the $C_{4}$ coefficient was calculated using

$$
C_{4}=C_{4}^{\prime} \frac{\left(d_{3}-d_{2}\right)}{d_{3}},
$$

where

$$
C_{4}^{\prime}=\frac{\tau}{\left(t_{1}-t_{0}\right)}
$$

The $e$-folding time of the departure of the soil moisture gradient from its initial value (at $t_{0}$ ) is represented by $t_{1}-t_{0}$. The dependence of $C_{4}$ on $d_{2}$ and $d_{3}$ in Eq. (17) results from the water conservation factor in Eq. (3) [Eq. (14)]. The $C_{4}^{\prime}$ values then were fit as a function of soil moisture at time $t_{1}$ using a two-parameter regression equation of the form

$$
C_{4}^{\prime}=C_{4 \mathrm{ref}} \bar{w}_{2,3}^{C_{4 b}} .
$$

The interfacial value of the water content for layers two and three is represented by $\bar{w}_{2,3}$ (appendix A). The fitting form used in Eq. (16) was selected because it closely resembles the functional form of the diffusion coefficient from Darcy's law using the empirical relations from CH78 [Eq. (12b)]. The $C_{4}$ coefficient becomes larger with increasing soil water content $\bar{w}$, as it is proportional to the hydraulic conductivity.

\section{2) DifFusion COEFFICIENT SCALING}

The parameter $C_{4 b}$ in Eq. (19) depends upon soil texture only, while $C_{4 \text { ref }}$ is related to both the texture and the thickness of the model layers. These two model parameters were calibrated using a variety of grid configurations so that $C_{4}$ values depend upon the soil texture, and, in theory, a separate set of values as a function of texture is needed for every possible combination of $d_{2}$ and $d_{3}$. As opposed to using separate $C_{4}$ values for various grid configurations, this coefficient can be scaled as a function of grid geometry. The result is that only one set of $C_{4 b}$ and $C_{4 \text { ref }}$ values that depend on soil texture are required for any grid configuration (values of $d_{2}$ and $d_{3}$ ) to calculate $C_{4}$.

The dependence of vertical diffusion on the grid configuration can be seen by writing the vertically integrated equation of continuity of soil moisture for a onedimensional homogeneous soil column (Richards's equation):

$$
\rho_{w} \int_{z_{i-1}}^{z_{i}} \frac{\partial \eta}{\partial t} d z=-\int_{z_{i-1}}^{z_{i}} \frac{\partial W_{s}}{\partial z} d z
$$

where $W_{s}$ is defined by Eq. (10), and $\eta$ represents the volumetric water content of the soil $\left(\mathrm{m}^{3} \mathrm{~m}^{-3}\right)$. The layeraveraged volumetric water content for soil layer $i$ is defined as

$$
w_{i}=\frac{1}{\left(z_{i}-z_{i-1}\right)} \int_{z_{i-1}}^{z_{i}} \eta(z) d z
$$

so that the integration of Eq. (20) over the layer bounded by $z_{i}$ and $z_{i-1}$ yields

$$
\rho_{w}\left(z_{i}-z_{i-1}\right) \frac{\partial w_{i}}{\partial t}=\left.W_{s}\right|_{z_{i-1}}-\left.W_{s}\right|_{z_{i}} .
$$

Assuming no drainage, the soil water flux at $z=d_{2}$ is written from Eqs. (10) and (12a) as

$$
\left.W_{s}\right|_{z=d_{2}}=\left.\rho_{w} \mathcal{D} \frac{\partial w}{\partial z}\right|_{z=d_{2}} .
$$

Using the boundary condition from Eq. (11a), the prognostic equation for the layer-averaged volumetric water content for the layer extending from $z_{i-1}=0$ to $z_{i}=$ $d_{2}$ can be written from Eqs. (22) and (23) as 
TABLE 1. The soil texture classes from $\mathrm{CH} 78$ and the $C_{4}$ fitting parameters. The symbols $X_{\text {clay }}$ and $X_{\text {sand }}$ represent the clay and sand percentages, respectively. Sand fractions are from Cosby et al. (1984). The $C_{4}$ coefficient is evaluated for a total soil column depth $d_{3}$ of 2 $\mathrm{m}$ and a root zone depth $d_{2}$ of $1 \mathrm{~m}$ at a mean water content $\bar{w}$ defined here as the average of the wilting-point and field capacity values. The $C_{4 \text { ref }}$ values can be scaled for any grid configuration using the $C^{\prime}{ }_{4 \text { ref }}$ values shown here together with Eq. (21).

\begin{tabular}{lrrrrc}
\hline \hline \multicolumn{1}{c}{ Soil type } & $\begin{array}{r}X_{\text {clay }} \\
(\%)\end{array}$ & $\begin{array}{c}X_{\text {sand }} \\
(\%)\end{array}$ & \multicolumn{1}{c}{$C_{\text {4ref }}^{\prime}$} & $C_{4 b}$ & $\begin{array}{c}C_{4}(\bar{w}) \\
\left(\times 10^{-2}\right)\end{array}$ \\
\hline Sand & 3 & 92 & 25096 & 5.8 & 1.85 \\
Loamy sand & 6 & 82 & 19485 & 6.0 & 4.70 \\
Sandy loam & 9 & 58 & 4623 & 6.4 & 1.66 \\
Silt loam & 14 & 17 & 736 & 6.9 & 0.23 \\
Loam & 19 & 43 & 518 & 6.4 & 0.96 \\
Sandy clay loam & 28 & 58 & 3835 & 7.8 & 2.50 \\
Silty clay loam & 34 & 10 & 546 & 8.3 & 0.40 \\
Clay loam & 34 & 32 & 2257 & 9.3 & 0.40 \\
Sandy clay & 43 & 52 & 18526 & 10.6 & 1.58 \\
Silty clay & 49 & 6 & 3059 & 11.1 & 0.22 \\
Clay & 63 & 22 & 6089 & 11.5 & 0.74 \\
\hline
\end{tabular}

$$
\begin{aligned}
d_{2} \frac{\partial w_{2}}{\partial t} & =-\frac{\mathcal{D}\left(\bar{w}_{2,3}\right)\left(w_{3}-w_{2}\right)}{\left[\left(d_{3}+d_{2}\right) / 2-d_{2} / 2\right]} \\
\frac{\partial w_{2}}{\partial t} & =\frac{2 \mathcal{D}\left(\bar{w}_{2,3}\right)}{d_{2} d_{3}}\left(w_{2}-w_{3}\right) .
\end{aligned}
$$

A linear variation of $w$ between layer midlevels is assumed when writing the finite difference of $\partial w / \partial z$ (Mahrt and Pan 1984) in Eq. (24). Comparison of Eqs. (24) and (13) yields

$$
C_{4} \propto \frac{2 \tau\left|\mathcal{D}\left(\bar{w}_{2,3}\right)\right|}{d_{2} d_{3}} .
$$

Note that there is a sign difference between Eqs. (24) and (13) because $\mathcal{D}$ is less than 0 [see Eq. (12b)]. The right-hand side of Eq. (25) represents the nondimensional diffusion from the Richards equation scaled by the time period $(\tau)$ of one day. The thickness of the soil layer is denoted by $d_{2}$ and $d_{3} / 2$ represents the distance over which the soil water gradient is calculated.

The dependence of $C_{4}^{\prime}$ on grid geometry for two soil layers can be determined to a good approximation by scaling $C_{4 \text { ref }}$ using the scaling factor from Eq. (25):

$$
C_{4 \mathrm{ref}}=C_{4 \mathrm{ref}}^{\prime} d_{2}^{\prime} d_{3}^{\prime} /\left(d_{2} d_{3}\right),
$$

where $C_{4 \text { ref }}^{\prime}$ represents reference values computed for a single nominal grid configuration. The $C_{4 \text { ref }}^{\prime}$ values are shown in Table 1 , and $d_{2}^{\prime}$ and $d_{3}^{\prime}$ represent the corresponding layer depths of 1 and $2 \mathrm{~m}$, respectively. Examples of scaled values of $C_{4 \text { ref }}$ are shown in Fig. 2 for two different grid configurations: $d_{2}=0.5$ and $d_{3}=$ $1.0 \mathrm{~m}$ in panel a and $d_{2}=2.0$ and $d_{3}=4.0 \mathrm{~m}$ in panel b. The $C_{4 \text { ref }}^{\prime}$ values from Table 1 are scaled using Eq. (26) and are shown as a function of the corresponding $C_{4 \text { ref }}$ values. Each filled circle corresponds to a particular soil class. The scaling approximation in Eq. (26) remains valid for a reasonable choice of $d_{2}$ and $d_{3}$ : in
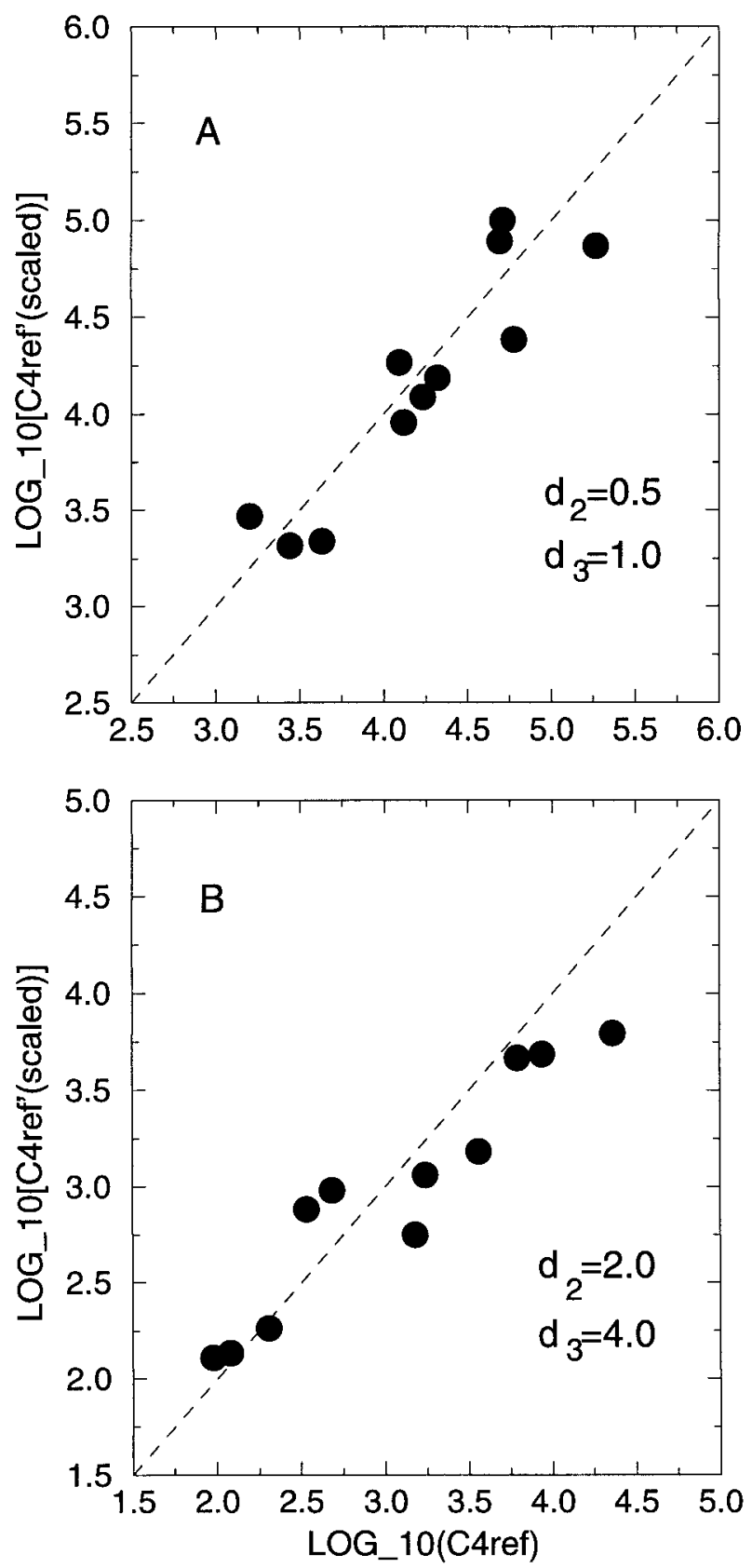

FIG. 2. The log-transformed $C_{\text {4ref }}$ values as computed from MLSM corresponding to $d_{2}=0.5$ and $d_{3}=1.0 \mathrm{~m}$ in (a) and to $d_{2}=2.0$ and $d_{3}=4.0 \mathrm{~m}$ in (b). The ordinate represents the log-transformed values of $C_{4 \text { ref }}$ scaled using Eq. (26) with the $C_{4 \text { ref }}^{1}$ values shown in Table 1. Each filled circle corresponds to a particular soil class. The dashed line indicates a 1:1 relationship.

general, the upper limit of the ratio $d_{3} / d_{2}$ is approximately an order of magnitude.

Substitution of Eqs. (19) and (26) into Eq. (17) results in

$$
C_{4}=\frac{\left(d_{3}-d_{2}\right) d_{2}^{\prime} d_{3}^{\prime}}{d_{2} d_{3}^{2}} C_{4 \mathrm{ref}}^{\prime} \bar{w}_{2,3}^{C_{4 b}}
$$




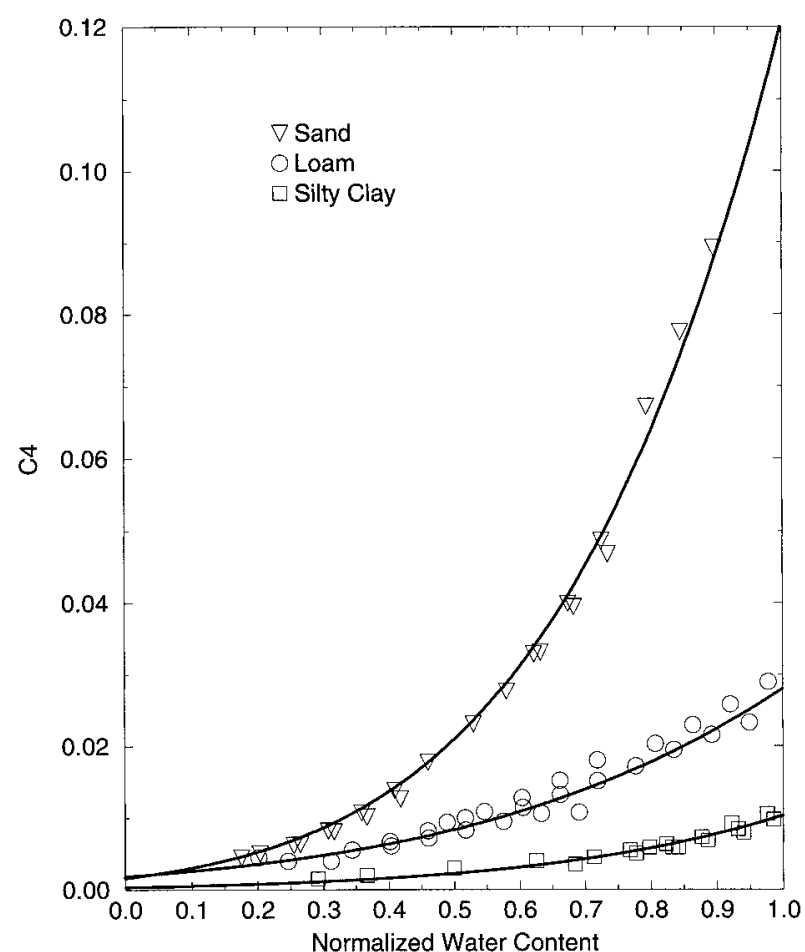

FIg. 3. The $C_{4}$ dimensionless coefficient as a function of the interfacial volumetric water content, $\bar{w}_{2,3}$, for sand, loam, and silty clay soil textures. The interfacial water content has been normalized for each soil texture: the minimum value along the abscissa represents the wilting point, and unity represents the field capacity. The total soil depth $d_{3}$ is $2 \mathrm{~m}$, and the root zone depth $d_{2}$ is $1 \mathrm{~m}$. Symbols represent results calculated from MLSM using Eqs. (17) and (18). The fits using Eqs. (17) and (19) are shown as solid lines. The corresponding fit coefficients are shown in Table 1.

The $C_{4}$ coefficient depends upon grid geometry, soil moisture at the layer interface, and soil texture from Eq. (27).

The $C_{4}$ coefficients computed from MLSM for three soil textures (sand, loam, and silty clay) are shown in Fig. 3, where the symbols represent results from MLSM for a soil with a total depth $\left(d_{3}\right)$ of $2 \mathrm{~m}$ and a root zone depth $\left(d_{2}\right)$ of $1 \mathrm{~m}$. The coefficient $C_{4}$ was calculated from Eqs. (17) and (18). The $C_{4 b}$ and $C_{4 r e f}$ fitting parameters then were determined by doing a least squares regression on the $C_{4}$ coefficients calculated from MLSM output data using Eqs. (17) and (19); the fits are shown as solid curves in Fig. 3. The fit parameters for each soil class as a function of the aforementioned grid configuration are shown in Table 1.

\section{3) Continuous Relationships}

Continuous relationships can be obtained that relate the $C_{4}$ force-restore coefficient to the soil texture through specification of the percentages of clay $X_{\text {clay }}$ and sand $X_{\text {sand }}$ (Noilhan and Lacarrère 1995). There are two parameters to fit that vary as a function of soil texture from Eq. (19): $C_{4 b}$ and $C_{4 \text { ref }}$. The $C_{4 b}$ parameter is fit

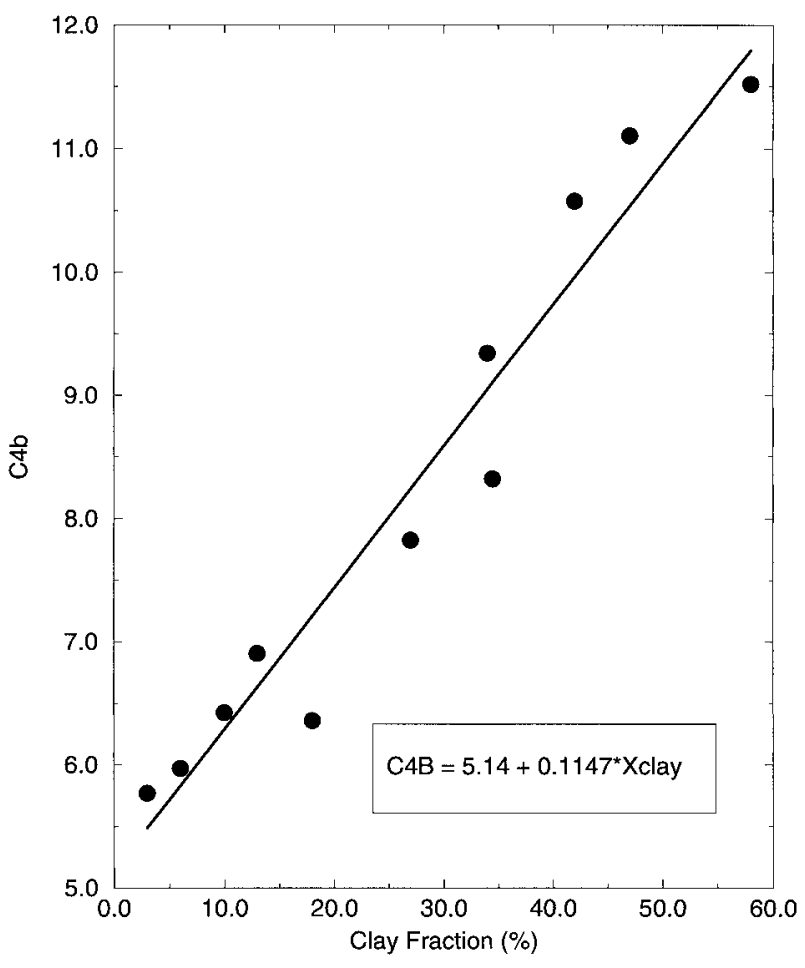

FIG. 4. The $C_{4 b}$ coefficient as a function of clay fraction $X_{\text {clay. }}$. The parameter values from Table 1 are shown as shaded circles, and the fit [Eq. (25a)] is indicated by the solid line.

as a linear function of clay fraction to a good approximation (Fig. 4) using

$$
C_{4 b}=5.14+0.115 X_{\text {clay }} \text {. }
$$

A multivariate least squares regression is used to compute $C_{4 \text { ref }}$ as a function of both $X_{\text {clay }}$ and $X_{\text {sand }}$ using

$C_{4 \text { ref }}=\frac{2\left(d_{3}-d_{2}\right)}{\left(d_{2} d_{3}^{2}\right)} \log _{10}^{-1}\left[\beta_{0}+\sum_{j=1}^{3}\left(\beta_{j} X_{\text {sand }}^{j}+\alpha_{j} X_{\text {clay }}^{j}\right)\right]$,

where $\beta$ and $\alpha$ are the coefficients obtained from a multivariate least squares regression. The regression coefficients are given in Table 2. A comparison of $C_{4 \text { ref }}$ values from Table 1 and those computed using the continuous relationship (indicated as $C_{4 \text { ref* }}$ ) for a soil with the same grid geometry are shown in Fig. 5. Relation-

TABLE 2. The regression coefficients for $C_{4 \text { ref }}$ from Eq. (28b). Values of $C_{4 \text { ref }}$ are calculated using the soil sand and clay percentages. The coefficients $\beta_{j}$ and $\alpha_{j}$ correspond to the sand and clay contents (\%), respectively.

\begin{tabular}{ccc}
\hline \hline$j$ & \multicolumn{1}{c}{$\beta_{j}$} & \multicolumn{1}{c}{$\alpha_{j}$} \\
\hline 0 & $4.42 \times 10^{-0}$ & \\
1 & $4.88 \times 10^{-3}$ & $-2.57 \times 10^{-1}$ \\
2 & $5.93 \times 10^{-4}$ & $8.86 \times 10^{-3}$ \\
3 & $-6.09 \times 10^{-6}$ & $-8.13 \times 10^{-5}$ \\
\hline
\end{tabular}




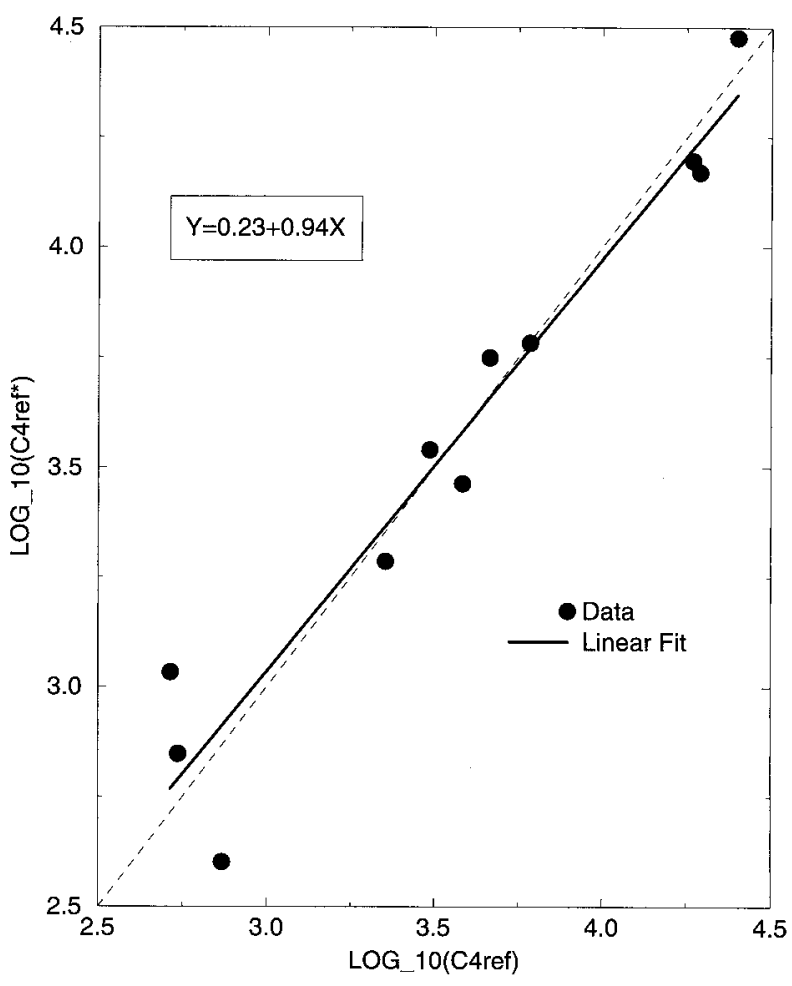

FIG. 5. The log-transformed $C_{4 \text { ref }}$ values computed using a continuous relationship $\left(C_{4 \text { ref* }}\right)$ as a function of clay and sand percentages ( $X_{\text {clay }}$ and $X_{\text {sand }}$, respectively) are shown versus the values for each CH78 soil class (Table 1) for a total soil depth $d_{3}$ of $2 \mathrm{~m}$, and a root zone depth $d_{2}$ of $1 \mathrm{~m}$. The continuous relationship is given by Eq (25b). The solid line represents a linear fit to the points, while the dotted line represents a 1:1 relationship.

ships for the other ISBA force-restore coefficients can be found in appendix A.

\section{Soil moisture simulations}

The ISBA-3L scheme is validated through the use of case studies comprising annual cycles of atmospheric forcing, observed soil moisture, measured or estimated vegetation parameters, and, possibly, surface fluxes. The atmospheric forcing needed to drive an SVAT model such as ISBA consists of surface pressure, air temperature and humidity at screen level, downward radiation fluxes (shortwave and longwave components), wind speed, and precipitation. Three studies that already have been used to validate ISBA-2L are presented in this paper: Hydrological Atmospheric Pilot Experiment-Modélisation du Bilan Hydrique (HAPEX-MOBILHY) (André et al. 1986, 1988; Goutorbe 1991), and National Institute for Agronomic Research (INRA)/Castanet (Cabelguenne et al. 1990; Calvet et al. 1998, hereinafter referred to as C98) irrigated (I) and nonirrigated (NI) experiments. The HAPEX-MOBILHY and INRA/Castanet-NI cases are useful for studying the vertical diffusion mechanism as plants are water stressed during prolonged summer periods. The INRA/Castanet-I case offers a comparison for nonstressed conditions. The hydrological model is validated using the measured soil water content and (for the HAPEX case) measured evapotranspiration.

There are many reasons for possible disagreement between the observed soil moisture and surface fluxes at the point scale and those computed by an SVAT model such as ISBA. Besides the use of relatively simple model physics, important sources for errors are related to the atmospheric forcing, the observations, and the model parameters. Atmospheric forcing generally is measured to within a reasonable accuracy, so that, assuming the model is able to simulate the most important physics, the model soil and vegetation parameters are the primary sources for discrepancy between the model simulation and observed values.

The soil hydrological parameters are based on a textural analysis [i.e., assuming texture is the most important soil descriptor (Cosby et al. 1984)] and are determined using regression relationships. These relations then are extrapolated to most known soil types, which is not always a valid approximation: Delire et al. (1997) showed that a new set of hydrological parameters was required to model some Amazonian soils properly using an SVAT scheme. There is much variability inherent in the parameters used in the regression relationships, and relatively small changes in soil texture values can result in large changes in the simulated soil moisture and, therefore, modeled evapotranspiration and runoff. Also, such possibly important considerations as vertical gradients in soil texture and the effect of macropores on infiltration and soil water fluxes are not modeled by the majority of SVAT schemes. For the case studies considered in this paper, it is assumed that the $\mathrm{CH} 78$ model and parameters are adequate.

There are many surface vegetation parameters that can affect the interaction between evapotranspiration and soil moisture. In ISBA, albedo, surface roughness length, vegetation coverage, leaf area index, and minimum stomatal resistance are the most important with respect to their impact on the calculation of surface fluxes of heat and moisture. Nearly all of these parameters can, in general, be obtained from measurements to within a reasonable accuracy with the exception of the minimum stomatal resistance $\left(R_{s \min }\right)$. It was shown by Niyogi and Raman (1997) using a Jarvis-type canopy resistance scheme (the scheme used by ISBA; see Noilhan and Planton 1989), that $R_{\text {smin }}$ is the most important vegetation parameter controlling the latent heat flux from the surface and therefore boundary layer development. Because of this high sensitivity and the fact that it usually is not measured directly, it is treated as a calibration parameter in ISBA. C98 showed that soil moisture and the components of the surface energy budget can be simulated quite well by tuning this parameter using the same case studies examined in this paper (in addition to others). Because the water stress factor (which is proportional to canopy resistance in ISBA) is 
evaluated using only the root zone soil water content in ISBA-3L, as opposed to the total soil water content used in ISBA-2L, $R_{s \min }$ was recalibrated for this study.

The root zone soil depth $\left(d_{2}\right)$ is the single new soil vegetation parameter in ISBA-3L. It usually is not measured for atmospheric modeling case studies, although depths typical of certain plant and soil types have been estimated on the global scale [see Canadell et al. (1996) for a review]. As will be seen, this parameter has an important impact on evapotranspiration as it is proportional to the amount of water that is available for transpiration. Evapotranspiration is sensitive to the total soil depth $\left(d_{3}\right)$, but this sensitivity is less important than that associated with $d_{2}$ [consistent with the findings of Liang et al. (1996)]; therefore model sensitivity to $d_{3}$ is not shown in this paper.

The final parameter that is examined is the wiltingpoint volumetric water content $\left(w_{\text {wilt }}\right)$. This parameter is a function of texture in ISBA, but values of this parameter that are inferred from observations can differ from those derived merely from textural considerations. The parameter $w_{\text {wilt }}$ represents the approximate lower limit of the root zone volumetric water content, so that it has an impact both on water available for transpiration and on vertical soil moisture diffusion (by influencing the magnitude of the vertical soil moisture gradient).

While other soil vegetation parameters can have an effect on the surface energy and hydrological budgets, an analysis of the effects of all of these parameters is beyond the scope of this text. In this study, model sensitivity to three key parameters that control evapotranspiration, and therefore modulate the vertical soil moisture gradient and diffusion, is examined. The wiltingpoint water content, minimum stomatal resistance, and depth of the rooting zone were determined to be the three most important parameters related to the incorporation of a distinct root zone soil reservoir.

\section{a. The HAPEX-MOBILHY simulation}

The HAPEX-MOBILHY experiment took place in southwestern France in 1986 over a domain of approximately $1^{\circ}$ latitude $\times 1^{\circ}$ longitude. This particular case is of interest since high temporal resolution measurements are available for the atmospheric forcing, surface flux observations are available, weekly soil moisture measurements were taken over the entire year (Goutorbe et al. 1989), and there is a good characterization of the surface soil and vegetation properties. This dataset was used during the Regional Interactions of Climate and Ecosystems (RICE) and PILPS workshop to assess the ability of SVAT schemes to model adequately all the components of the water cycle at a spatial scale on the order of a climate model grid box (Shao et al. 1994). The same atmospheric forcing, soil and vegetation parameter values, spinup requirements, and observed soil moisture and surface fluxes that were used for PILPSHAPEX are also used for this simulation, since they
TABLE 3. Vegetation and soil hydrological constant (in time) parameters used for the HAPEX-MOBILHY, Castanet-I, and CastanetNI simulations. Values correspond to those used with ISBA-3L and ISBA-2L. The surface albedo and emissivity are represented by $A$ and $\epsilon$, respectively. The values that differ between the two model configurations (and correspond to ISBA-2L) are enclosed by parentheses.

\begin{tabular}{llccc}
\hline \hline Parameter & Units & HAPEX & Castanet-I & Castanet-NI \\
\hline$R_{\text {smin }}$ & $\mathrm{s} \mathrm{m}^{-1}$ & 150 & $31(88)$ & $32(135)$ \\
$A$ & & 0.20 & 0.20 & 0.20 \\
$\epsilon$ & & 1.0 & 0.97 & 0.97 \\
$w_{\text {fc }}$ & $\mathrm{m}^{3} \mathrm{~m}^{-3}$ & 0.31 & 0.34 & $0.40(0.35)$ \\
$w_{\text {wilt }}$ & $\mathrm{m}^{3} \mathrm{~m}^{-3}$ & $0.15(0.20)$ & 0.16 & 0.16 \\
$d_{2}$ & $\mathrm{~m}$ & $1.1(1.6)$ & 1.6 & 1.6 \\
$d_{3}$ & $\mathrm{~m}$ & 1.6 & 5.0 & 5.0 \\
$X_{\text {clay }}$ & $\%$ & 34.0 & 28.0 & $28.0(25.8)$ \\
$X_{\text {sand }}$ & $\%$ & 10.0 & 35.0 & $35.0(47.4)$ \\
\hline
\end{tabular}

were used in the presentation of the introduction of gravitational drainage in the ISBA scheme (MN96). A description of the PILPS-HAPEX experiment(s), atmospheric forcing, observations used for validation and intercomparison of the SVAT schemes, and a comprehensive listing of specified model parameters can be found in Shao and Henderson-Sellers (1996).

The surface is characterized as a soybean crop over a loamy soil (Goutorbe 1991), and the soil column is assumed to have a homogeneous texture profile that extends to a total depth $\left(d_{3}\right)$ of $1.6 \mathrm{~m}$. Soil moisture was measured on an approximately weekly basis at $10-\mathrm{cm}$ increments for the entire soil column. The total annual observed precipitation was $856 \mathrm{~mm}$. The daily average evapotranspiration was computed from the HAPEX forcing data using the Penman-Monteith equation, and the annual total is $615 \mathrm{~mm}$. The net radiation, ground heat, and sensible heat fluxes were measured at 15-min intervals during an intensive observation period (IOP) over yeardays 148-183. The latent heat flux then was calculated as a residual from the surface energy balance.

All precipitation in excess of evaporation was assumed to be runoff. The root system was not observed or measured, so a root distribution was specified for PILPS-HAPEX based on values that are typical of a soybean crop over a loamy soil for a similar climate (Shao and Henderson-Sellers 1996).

\section{1) PARAmeter SEnsitivity}

The values for constant vegetation and soil hydrological parameters, following the PILPS-HAPEX specifications (Shao and Henderson-Sellers 1996), used by ISBA-2L and ISBA-3L for the HAPEX simulation are shown in Table 3. Values enclosed by parentheses correspond to those used by ISBA-2L when different from those used by ISBA-3L. The vegetation parameters used in ISBA that vary as a function of time can be found in MN96. Of the three key ISBA parameters that link soil moisture to evapotranspiration, $R_{\text {smin }}$ was determined by calibrating ISBA-3L using the observed 
evapotranspiration data. A value of approximately 150 $\mathrm{s} \mathrm{m}^{-1}$ resulted in the best agreement with the daily and annually averaged latent heat fluxes. This value is the same as that used in C98 and MN96 (which also used the PILPS-HAPEX specifications). Several values were specified by PILPS-HAPEX for $w_{\text {wilt }}$ and a range was specified for $d_{2}$, so the effect on the modeled soil water profile of varying the latter two parameters is examined in more detail.

Two distinct model groupings could be seen from the PILPS-HAPEX workshop evapotranspiration results, based on the specified values of $w_{\text {wilt }}$ (Mahfouf et al. 1996): bulk (single root zone/base flow) soil layer models such as ISBA-2L performed best with respect to the observed evapotranspiration when a value of $0.20 \mathrm{~m}^{3}$ $\mathrm{m}^{-3}$ was used, while multilayer models performed best when values in the range from 0.15 to $0.12 \mathrm{~m}^{3} \mathrm{~m}^{-3}$ were used. This result is primarily because the soil water available for transpiration by plants can be approximated as $d_{2}\left(w_{\mathrm{fc}}-w_{\text {wilt }}\right)$, where $d_{2}$ is the soil depth that contains plant roots. Multilayer models used values of $d_{2}$ that were less than the total soil depth of $1.6 \mathrm{~m}$, so to have the same available water content for transpiration as do the bulk models, $w_{\text {wilt }}$ must be reduced. The value of $0.20 \mathrm{~m}^{3} \mathrm{~m}^{-3}$ was derived from textural considerations, whereas $0.15 \mathrm{~m}^{3} \mathrm{~m}^{-3}$ is more representative of the observations (Shao and Henderson-Sellers 1996). Since ISBA-3L falls into the class of multilayer models, the latter value is used for the soil moisture simulation presented in this study, thus maintaining approximately the same amount of available soil water for transpiration with respect to ISBA-2L.

The single additional model parameter needed by ISBA-3L, compared to ISBA-2L, is the depth of the rooting zone $\left(d_{2}\right)$. The value of this parameter essentially controls the amount of soil water that is available for transpiration by plants and thus is especially important for surfaces with a significant vegetation coverage. Specification of $d_{2}$ becomes important for bare soil surfaces when it is decreased to values that approach the daily evaporation-wave penetration depth. Runs were made, using the HAPEX forcing and parameters, in which only $d_{2}$ was varied.

Three tests or sets of runs were made: a totally vegetated surface (veg $=1$ ), a vegetation-free surface (veg $=0$ ), and the HAPEX-default vegetation coverage (in which veg ranges from 0 during winter months to 0.5 in the spring to 0.9 during the summer: see MN96 for monthly mean values). The annually averaged evapotranspiration ratios for the three tests are shown in Fig. 6 as a function of the grid-depth ratio $d_{2} / d_{3}$. The evapotranspiration ratio is defined as the ratio of the annually averaged evapotranspiration from ISBA-3L to the value from ISBA-2L for each of the three tests so that as $d_{2}$ approaches $d_{3}$, the evapotranspiration and grid-depth ratios approach unity. As $d_{2}$ approaches zero, the evapotranspiration ratio decreases because of the reduction in the water available for transpiration.

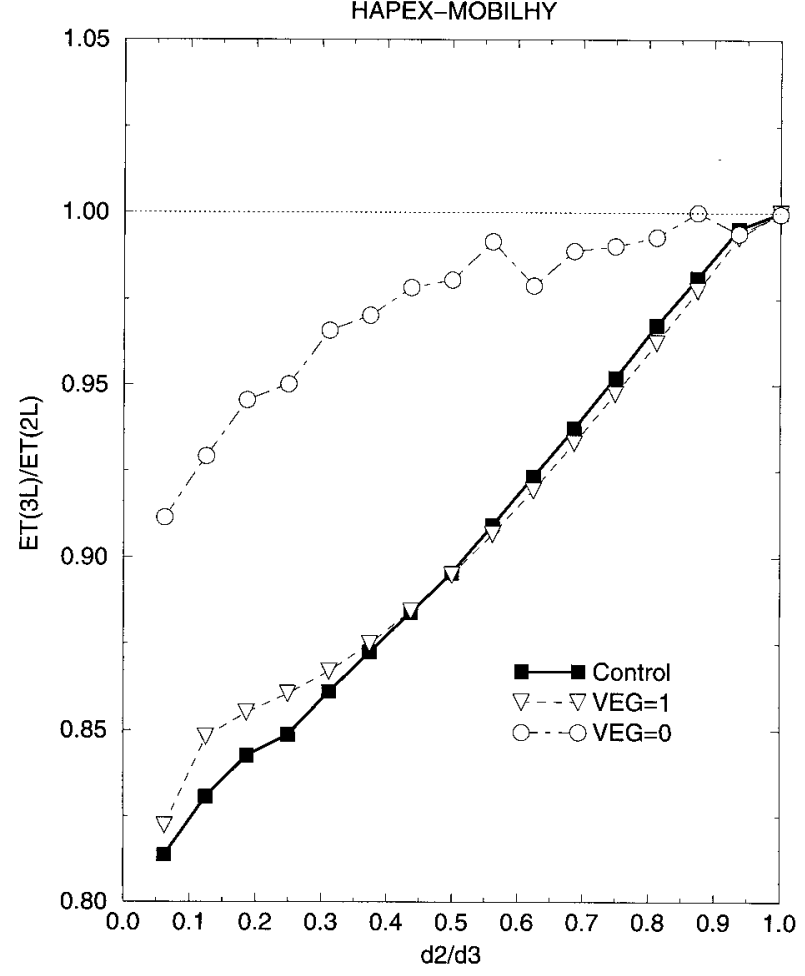

Fig. 6. Model output evapotranspiration sensitivity to the depth of the rooting zone $d_{2}$. The total soil depth $d_{3}$ is fixed at $1.6 \mathrm{~m}$. Evapotranspiration is reduced nearly linearly (by nearly 20\%) as the holding capacity or depth of the root zone decreases for a totally vegetated surface (triangles). The total annual evaporation from a surface with no vegetation is much less sensitive to the choice of $d_{2}$ (circles). The sensitivity is also shown using the HAPEX vegetation parameter forcing (boxes).

The evapotranspiration ratio over a completely vegetated surface increases nearly linearly as the soil rooting depth increases from an initial value of $0.1 \mathrm{~m}$ (triangles): total annual evapotranspiration is approximately $20 \%$ less than the bulk soil model value when $d_{2} / d_{3}$ $=0.06$. The bare soil case (circles) shows little sensitivity to this parameter until the ratio $d_{2} / d_{3}$ becomes less than approximately 0.5 ; the reduction in evapotranspiration from ISBA-3L relative to that from ISBA-2L is approximately $10 \%$ when $d_{2} / d_{3}=0.06$. The case using the default HAPEX parameters (filled squares) is very similar to the totally vegetated case until $d_{2} / d_{3}$ is decreased to approximately 0.5 . This similar behavior results because bare soil evaporation shows little sensitivity to $d_{2} / d_{3}$ at values above 0.5 , and the surface had partial or nearly full vegetation cover for the entire summer. The control evapotranspiration ratio has an increased sensitivity with respect to the veg $=1$ case when $d_{2} / d_{3}<0.5$. The rate of change of evapotranspiration ratio with respect to the grid-depth ratio is larger for the veg $=0$ case than for the veg $=1$ case when $d_{2} / d_{3}$ $<0.5$ : the surface is partially bare in the spring and fall months so that the evapotranspiration ratio for the control case shows effects of both the bare soil and vege- 


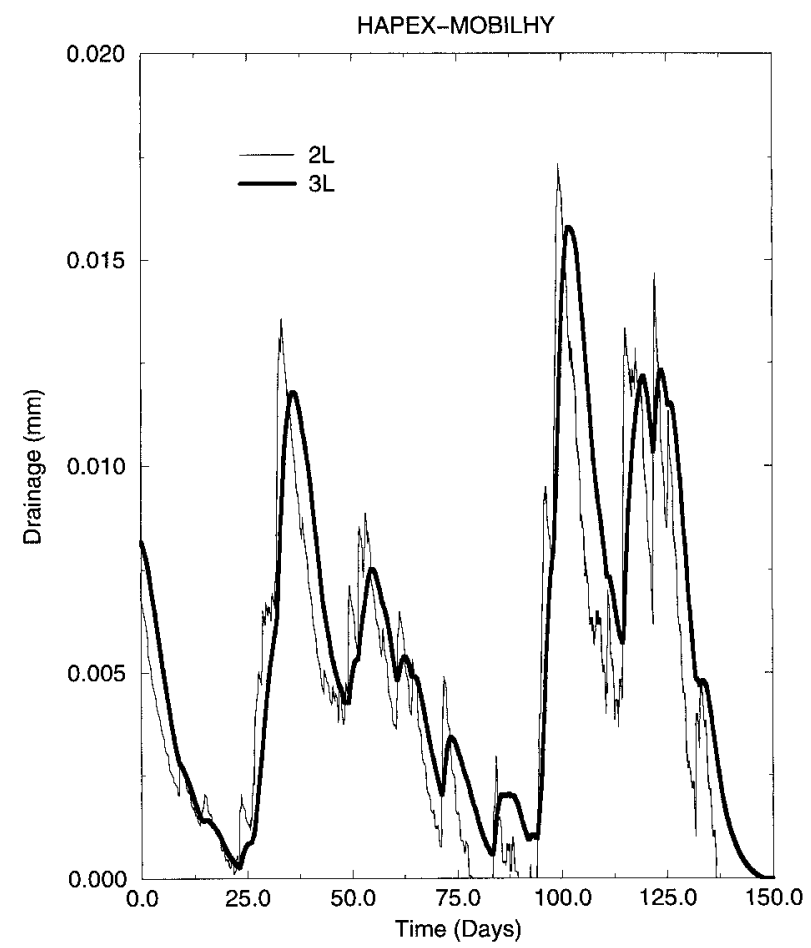

FIG. 7. Time series of drainage $(\mathrm{mm})$ out of the model base for the first 150 days of the HAPEX-MOBILHY simulation. The thin line corresponds to ISBA-2L; the thick line corresponds to ISBA-3L.

tated portions of the surface when $d_{2} / d_{3}$ is reduced sufficiently.

From the experiments using the default HAPEX parameters, a value of $d_{2}=1.1 \mathrm{~m}$ resulted in the best agreement with the estimated annual total $(615 \mathrm{~mm})$ for annually averaged evapotranspiration. This value of $d_{2}$ seems reasonable since $10 \%$ of the plant roots were assumed to exist in the layer from 0.5 to $1.6 \mathrm{~m}$ (Shao and Henderson-Sellers 1996).

\section{2) RUNOFF}

A greater timescale separation of the surface and base flow runoff components is attained by using distinct infiltration (root zone) and drainage layers. Model drainage does not respond to evapotranspiration and infiltration instantaneously in ISBA-3L because these sources (or sinks) are not added directly to (extracted from) the lowest layer (Fig. 1). The drainage time series for the first 150 days of the simulations for ISBA-3L (thicker curve) and ISBA-2L are shown in Fig. 7. The runoff peaks are lagged by an average of approximately four days for ISBA-3L relative to those for ISBA-2L, and their amplitude is reduced so that the ISBA-3L drainage time series more closely resembles a stream hydrograph. Drainage ceases during yearday 137 for ISBA-2L but it continues for approximately 10 days longer for ISBA$3 \mathrm{~L}$. No quantitative runoff time series data were available for comparison, but the effect on runoff in ISBA-
$3 \mathrm{~L}$ of adding a base flow layer currently is being addressed in other studies.

\section{3) Comparison with MLSM}

As a simple validation test of $C_{4}$, it is of interest to compare the diffusion produced by ISBA-3L to that computed by MLSM using the same forcing, parameters, surface physics (ISBA), and boundary conditions. MLSM is used as the "truth" since it is assumed to produce highly accurate solutions because the truncation errors are minimized. Vertical diffusion into the root zone should be most important during the growing season (GS) when a considerable soil moisture gradient can develop in response to large evaporative demand. To isolate the effects of diffusion, simulations using ISBA-3L and the coupled ISBA-MLSM models were performed in which the soil profiles were initialized at field capacity at the start of the HAPEX-MOBILHY GS and no precipitation was permitted, thus minimizing the effect of drainage on the model fluxes. A constant root distribution was used in the MLSM within the soil layers that encompass the root zone layer so as to be consistent with the single root zone layer of ISBA-3L. The HAPEX-MOBILHY GS began and ended on yeardays 148 and 273 , respectively.

The mean volumetric water content for the root zone $\left(w_{2}\right)$, subroot zone layer $\left(w_{3}\right)$, and total soil column $(w)$ from ISBA-MLSM and ISBA-3L for the GS are shown in Fig. 8. The thick lines (with circles) represent the results from MLSM, while thin lines (with stars) represent results from ISBA-3L. The reduction in water content in the lowest layer is caused entirely by vertical diffusion into the root zone, amounting to a total of 11 $\mathrm{mm}$ for this period for ISBA-3L or approximately $6 \%$ of the total evapotranspiration during the growing season (EGS). The total diffusion for MLSM is $15 \mathrm{~mm}$, or approximately $8 \%$ of the total EGS from MLSM, so that the portion of atmospheric evaporative demand met by diffusion of soil water from below the root zone differs by $2 \%$. The total evapotranspiration is $186 \mathrm{~mm}$ for MLSM and $187 \mathrm{~mm}$ for ISBA-3L, so that the total soil water content only differs by $1 \mathrm{~mm}$ between the two simulations on yearday 273. ISBA-3L reproduces the mean soil water profile (for the entire column) quite well for the 120-day period shown (yeardays 150-270), especially considering the difference in grid resolution (100 soil layers for MLSM versus 3 for ISBA-3L).

For comparison, integrations were performed using a direct solution of the Richards equation using the same soil water release functions [Eqs. (9a) and (9b)] and soil texture parameter values as are used by ISBA-3L. Equation (20) was integrated for the ISBA-3L geometry using the method of Mahrt and Pan (1984), which is used by many SVAT schemes in various forms. Additional integrations also were performed using Eq. (20) with another popular model among SVAT schemes, that of Sellers et al. (1986). The Sellers et al. method (SEA86) 


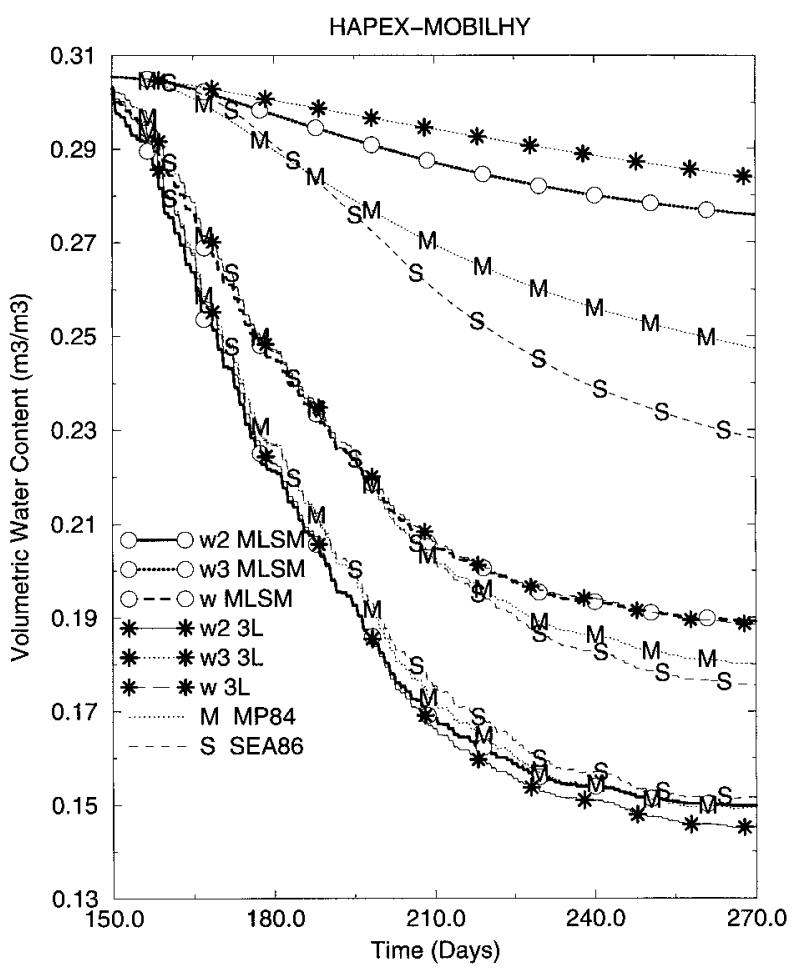

FIG. 8. Comparison of the time evolution of the volumetric soil water content among ISBA-3L, MLSM, MP84, and SEA86 for HAPEX-MOBILHY. The integration is over the growing season for yeardays 148-273. The models were initialized at field capacity on yearday 148, and precipitation was suppressed so as to compare the effects of the diffusion process across the base of the root zone (gravitational drainage was negligible). The mean soil water content of the root zone, the subroot zone, and the entire soil column are given by $w 2$, $w 3$, and $w$, respectively.

evaluates vertical diffusion using the gradient of the matric potential, and the diffusivity is calculated using the interpolated hydraulic conductivity. The Mahrt and Pan method (MP84) uses the vertical gradient of the volumetric water content, and the diffusivity is evaluated using the interpolated volumetric water content.

The resulting curves for the HAPEX GS are shown in Fig. 8; the simulations that correspond to MP84 are labeled with $\mathrm{M}$ and those that correspond to SEA86 are labeled with $\mathrm{S}$. The direct methods tend to overestimate vertical diffusion into the root zone from the layer below when a coarse grid geometry is used (total diffusion is $30 \mathrm{~mm}$ for MP84 and $39 \mathrm{~mm}$ for SEA86 compared to $15 \mathrm{~mm}$ from MLSM), which can lead to larger errors in total soil moisture and evapotranspiration than in ISBA-3L when compared to MLSM. This overestimate was also the case, in general, for different soil textures and three-layer grid configurations. Note that as the number of layers is increased using the direct methods the results approach those of the MLSM. These results show an example of how calibrating the coefficients for a low-resolution model (using a high-resolution model) can improve evapotranspiration estimates and total soil
TABLE 4. The water budget variables for HAPEX-MOBILHY. The annual totals for ISBA-2L and ISBA-3L are shown together with the observed values. RMS $(w d)$ represents the rmse in the total soil water with respect to the observed values. The total annual runoff, annual evapotranspiration, growing season evapotranspiration, and intensive observation period evapotranspiration are represented as RT, ET, EGS, and EIOP, respectively. All quantities are in millimeters.

\begin{tabular}{lccccc}
\hline \hline & RT & ET & EGS & EIOP & RMS $(w d)$ \\
\hline Obs & 241 & 615 & 316 & 127 & - \\
2L & 220 & 635 & 298 & 117 & 30.8 \\
3L & 241 & 613 & 310 & 111 & 28.4 \\
\hline
\end{tabular}

water in ISBA relative to a direct low-resolution model solution of the Richards equation with a similar geometry.

\section{4) HAPEX-MOBILHY ANNUAL CYCLE}

The ISBA-2L simulation of the water budget reproduced the annual cycles of the various components well compared to the observations (MN96), so that, while some improvement is possible using ISBA-3L, improvement should be limited for this particular case. The goal of this comparison is to see if a similar (if not slightly better) agreement with observations can be obtained using ISBA-3L and to examine any changes in partitioning or timing of the various water budget components.

The HAPEX-MOBILHY water budget variables in terms of annual totals for ISBA-2L, ISBA-3L, and the corresponding observations are shown in Table 4. ISBA2L and ISBA-3L produced nearly identical total soil water annual cycles (Fig. 9), but the total annual evapotranspiration is approximately $22 \mathrm{~mm}$ less for ISBA$3 \mathrm{~L}$, corresponding to an improvement relative to the observed total. The root-mean-square error (rmse) of the total soil water content also is improved slightly for ISBA-3L relative to ISBA-2L.

The EGS is slightly larger for ISBA-3L (and compares better with observations), even though overall evapotranspiration has decreased (implying decreased evapotranspiration outside of the growing season using ISBA-3L). The EIOP (evapotranspiration from the IOP) is underestimated using ISBA-3L. Note, however, that there is an inconsistency in the water budget for the IOP such that evaporation exceeds the residual of precipitation less soil water change by $25 \mathrm{~mm}$ (Mahfouf et al. 1996; Shao and Henderson-Sellers 1996), so that the ISBA-3L value falls within this range and might not, in fact, represent a degradation in results compared to ISBA-2L.

The annual cycle of the total soil water content is shown in Fig. 9. The solid thick curve represents the time series from ISBA-3L, the dashed line represents the results from ISBA-2L, and the solid squares correspond to the observed values. There is a slight improvement in total soil water content in spring, although it is still underestimated relative to the observations. In contrast, ISBA-3L is somewhat drier than ISBA-2L to- 


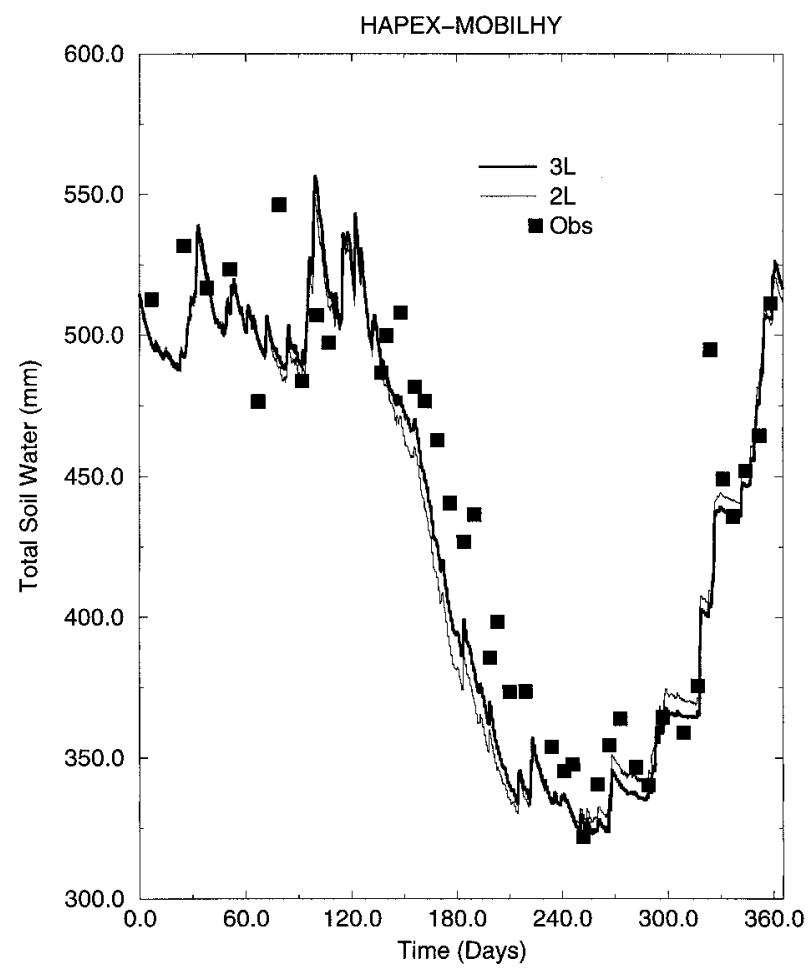

FIG. 9. Annual profile of the total soil water held within the soil reservoir. The thin line corresponds to the ISBA-2L result; the thick line corresponds to the ISBA-3L result. Observed soil water content is represented by the filled boxes.

ward the end of summer. Overall, the rmse in the total soil water content has decreased from 30.8 to $28.4 \mathrm{~mm}$ (Table 4), which represents a minor improvement.

The volumetric water content annual cycle from ISBA-3L is shown in Fig. 10. The modeled root zone soil water content is represented by a thin line, the subroot zone (or base flow) water content corresponds to the dashed line, and the solid thick curve represents the mean water content of the entire soil column. Observations are given by symbols for each layer. The soil water content of the root zone is in good agreement with the observations (circles), especially during summer. Note that the minimum observed volumetric water content values for the upper $1.1 \mathrm{~m}$ of the soil approach values that are very close to the specified value of $w_{\text {wilt }}$ $\left(0.15 \mathrm{~m}^{3} \mathrm{~m}^{-3}\right)$, implying that this value is reasonable on a physical basis (also corresponding well with $d_{2}=$ $1.1 \mathrm{~m})$.

The mean soil water content of the base flow layer does not agree quite as well with the observations in magnitude starting at approximately yearday 150, although the modeled rate of decrease is similar after yearday 240 . Note that the observed base flow moisture peak at approximately yearday 150 seems to have been induced by lateral inflow, possibly from a perched water table. Although there was some precipitation during the period of yeardays $140-150$, the change in the soil water

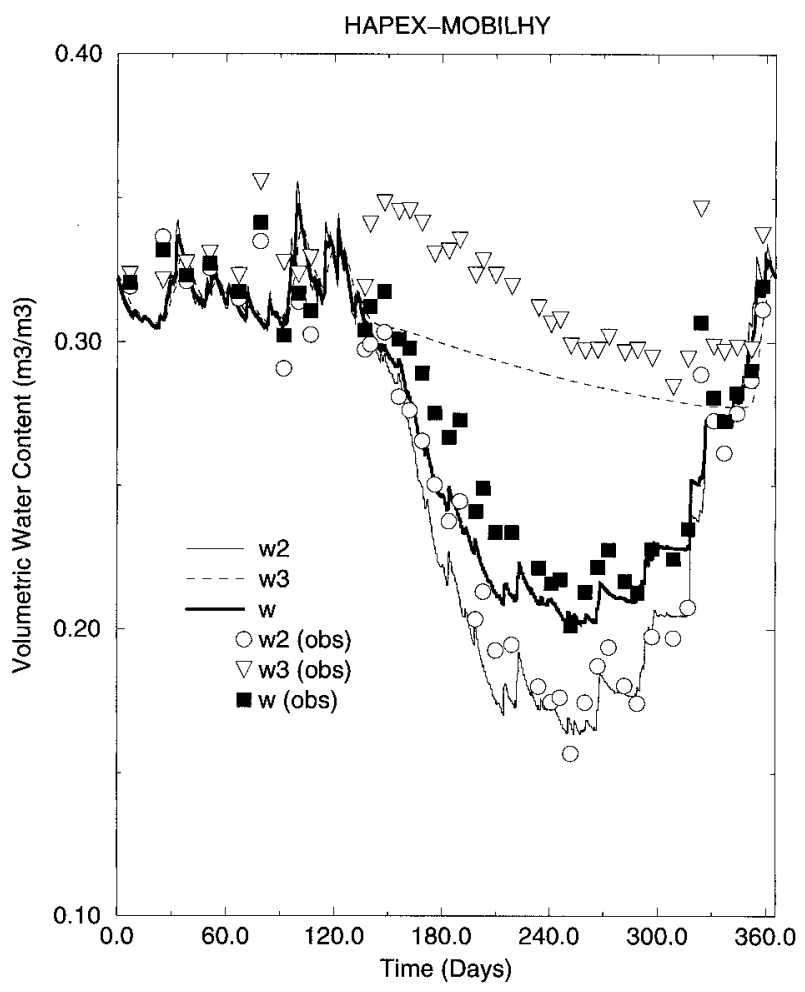

FIG. 10. HAPEX-MOBILHY annual cycle of the modeled volumetric soil water content for the two subsurface layers $w_{2}$ and $w_{3}$, and the total soil column mean volumetric water content $w$. The observed mean soil water content values corresponding to $w_{2}, w_{3}$, and $w$ are plotted using circles, triangles, and filled boxes, respectively.

for this period over the entire soil column exceeded the total precipitation from the forcing by approximately 10 $\mathrm{mm}$, which implies a lateral (or vertical) source of at least this magnitude (as evapotranspiration is occurring at the same time). Nearly all of this increase occurred in the soil layer below $1.1 \mathrm{~m}$. A change of $10 \mathrm{~mm}$ corresponds to an increase in $w_{3}$ of $0.02 \mathrm{~m}^{3} \mathrm{~m}^{-3}$. This increase corresponds well with the observations shown in Fig. 10: the increase in the observed $w_{3}$ over yeardays $140-150$ is approximately $0.03 \mathrm{~m}^{3} \mathrm{~m}^{-3}$. Obviously this moisture increase cannot be captured by the model using the forcing data "as are."

The daily average evapotranspiration for the entire year for ISBA-3L and ISBA-2L is shown in Fig. 11. Observed values are represented by the boxes. A 30day running mean was applied to all three evapotranspiration time series. The light-shaded areas represent a reduction in evapotranspiration in ISBA-3L (relative to ISBA-2L), while black-shaded areas represent the opposite effect. In the period prior to vegetation cover yeardays $0-119$ ) there is a slight reduction in evaporation, but the observations fall more or less in between the results from ISBA-3L and ISBA-2L, or both versions of ISBA overestimated the evaporation.

When vegetation cover begins $(50 \%$ coverage for 


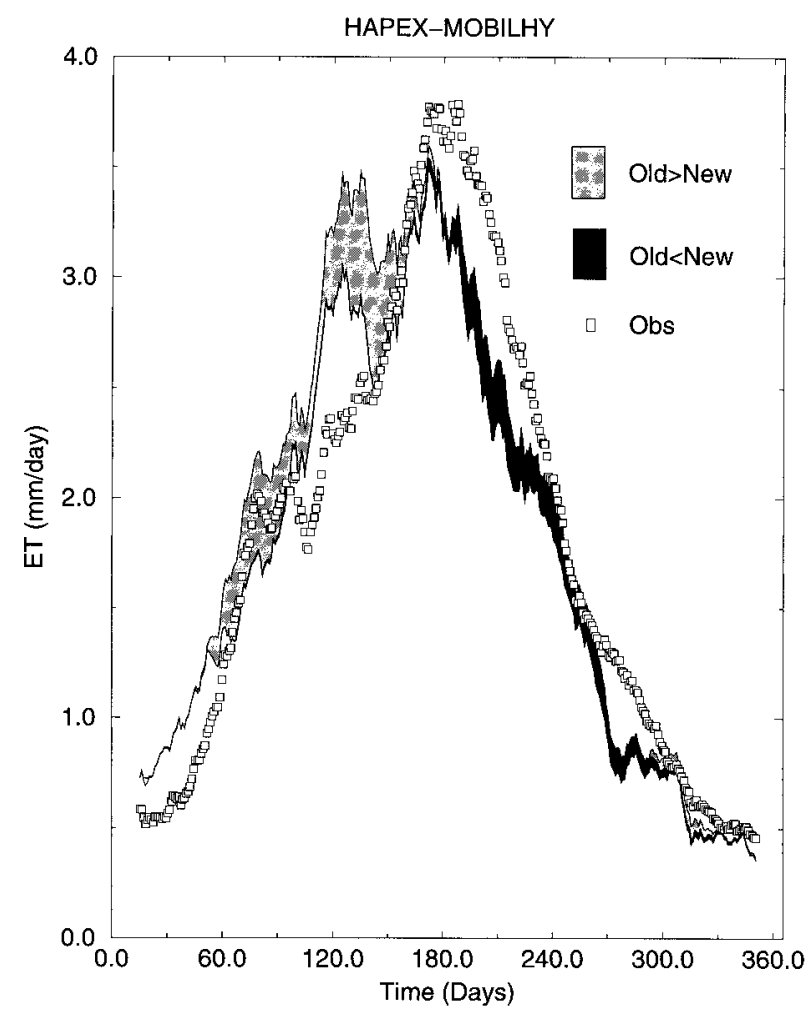

FIG. 11. Annual total daily evapotranspiration $\left(\mathrm{mm} \mathrm{day}^{-1}\right)$ for the ISBA-2L and ISBA-3L runs. The light-shaded areas indicate where evapotranspiration is less for ISBA-3L, and the dark-shaded regions are where evapotranspiration is larger for ISBA-3L. Observed daily totals are represented by the boxes. A 30-day running average was used for the model output and the observations.

yeardays 120-147), there is a reduction in evapotranspiration in ISBA-3L that represents an improvement relative to the observed values. This difference is from a reduction in bare soil evaporation (compared to ISBA$2 \mathrm{~L}$ ), which, in turn, is a result of using a smaller value of $w_{\text {wilt }}$ for the ISBA-3L simulation. Soil water is evaporated from the surface soil layer to the extent that $w_{g}$ approaches $w_{\text {wilt }}$ (especially early in this period), while further decreases in $w_{g}$ are minimal, since evaporation from the surface layer at water content values below $w_{\text {wilt }}$ in ISBA is a considerably slower process (Braud et al. 1993; Giordani et al. 1996). Lower values of $w_{g}$ for ISBA-3L result in lower ground surface relative humidity values, thereby causing decreased evaporation from the bare soil (see MN96) while transpiration changes are small by comparison. Although superior to ISBA-2L, ISBA-3L still overestimates evapotranspiration during the early part of this period. Because there are no soil moisture observations between yeardays 107-137, though, the exact causes for this overestimation are difficult to determine.

For yeardays 180-273, there is an increase in evapotranspiration for the ISBA-3L results and this increase, in general, better agrees with the observations. Bare soil evaporation is slightly less for the ISBA-3L case com- pared to that for ISBA-2L, but evapotranspiration is larger because of vertical soil moisture diffusion from below the root zone and the reduced water holding capacity of the root zone: volumetric water content values of layer two are larger after precipitation events for ISBA-3L, compared to values for ISBA-2L. This finding is consistent with the findings of Stamm et al. (1994), who determined that bulk soil models (such as ISBA2L) tend to underestimate evapotranspiration following rain events over relatively dry soils. While evapotranspiration has increased, though, it still is underestimated relative to the observed values between yeardays 180 and 240 . This discrepancy could be caused by a variety of factors related to the interaction between transpiration and soil water uptake, the most likely cause being the underestimation of soil moisture during this same period (Figs. 9 and 10) caused by the inability of the model to simulate what appears to be a subsurface soil water source. The evapotranspiration is nearly the same for the two versions of ISBA after the end of the growing season (after yearday 273) when vegetation is absent and energy input into the surface is low.

\section{b. The INRA/Castanet simulations}

The remaining case studies represent two sites from the INRA/Castanet experiment (Cabelguenne et al. 1990): irrigated and nonirrigated corn crops. The datasets consist of atmospheric forcing and vegetation parameters for the entire annual cycle of 1986, soil moisture measurements through the growing season at 10$\mathrm{cm}$ increments from the surface to soil depths of 1.6 and 1.7 (Castanet-I and -NI cases, respectively), and measured values of field capacity and wilting-point volumetric water content. Parameter values are shown in Table 3 . The soil is characterized as a sandy clay loam using the $\mathrm{CH} 78$ classification. The value of $d_{3}$ was set to the observed total soil depth of $5 \mathrm{~m}$ at Castanet (M. Cabelguenne 1997, personal communication). The soil texture and $w_{\mathrm{fc}}$ values were adjusted using observed values for Castanet-NI to values more representative of the 5-m soil depth for ISBA-3L. The latent heat flux was not measured for these cases, so model validation is performed using only the observed soil moisture data. The Castanet dataset was used in validation studies for ISBA-2L (C98).

\section{1) PARAMETER SENSITIVITY}

This set of case studies differs from HAPEX-MOBILHY in several aspects related to the three key model parameters that link the soil moisture and evapotranspiration. The parameter values for the Castanet-I and -NI experiments are shown in Table 3. The $R_{s \min }$ and $d_{2}$ parameters were optimized with respect to the observed soil water content. The values of $d_{2}$ ranged from 1.0 to 1.6 (1.7 for Castanet-NI) using increments of $0.1 \mathrm{~m}$. The optimum $d_{2}$ value for both cases was $1.6 \mathrm{~m}$, which 


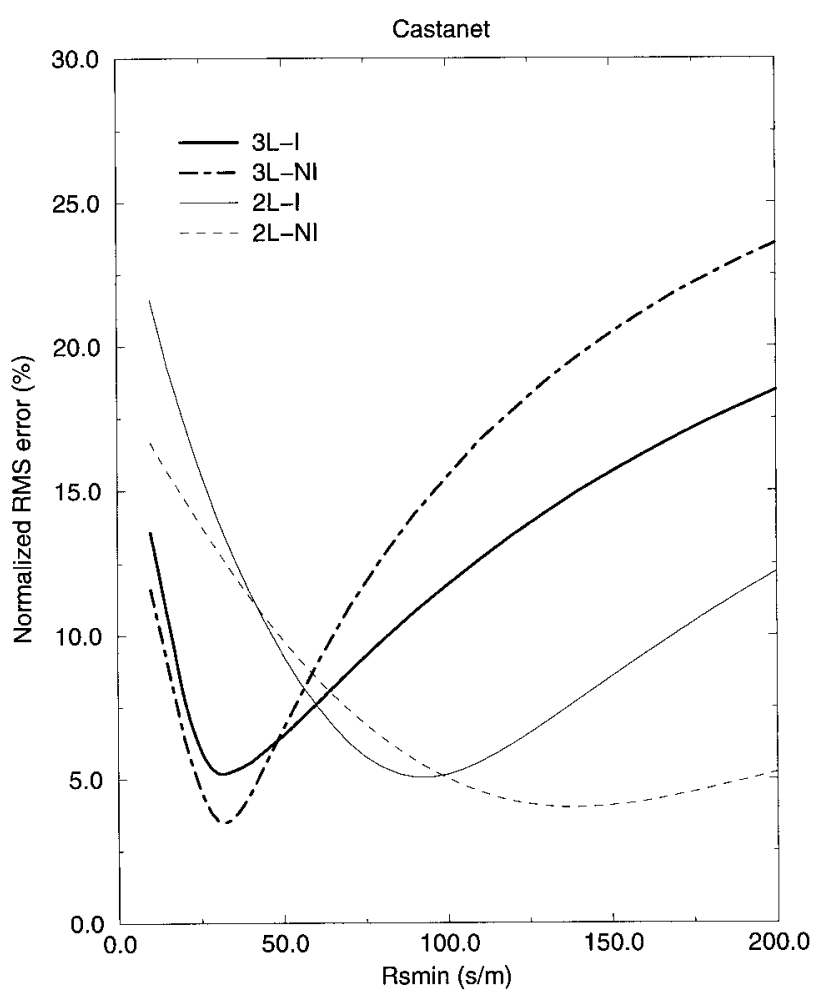

FIG. 12. Minimum stomatal resistance $R_{s \min }$ optimized with respect to the observed root zone soil moisture for the Castanet case studies. Curves are shown for both the irrigated (I) and nonirrigated (NI) cases for ISBA-3L and ISBA-2L. A root zone soil depth $d_{2}$ of 1.6 $m$ produced the best agreement between observations and the simulated soil moisture for both ISBA-3L cases.

is consistent with rooting depths for corn at this location. Note that the maximum values for $d_{2}$ were constrained by the depth of the observed soil moisture that was used for the optimization procedure, but analysis of the observations indicates that the bulk of the roots were distributed within this zone.

Unlike the HAPEX case where the original ISBA-2L model domain was divided for ISBA-3L to model accurately a distinct root zone, a subroot zone was added to ISBA-3L for Castanet while retaining the same geometry as ISBA-2L for the root zone. The wilting-point water content is the same for ISBA-2L and ISBA-3L for Castanet. This identity increases the amount of moisture available for transpiration for ISBA-3L relative to that for ISBA-2L because, while approximately the same amount of water is available in the root zone for transpiration, vertical diffusion can augment root zone soil moisture in ISBA-3L. The minimum stomatal resistance is tuned to obtain optimal agreement with soil moisture measurements (C98).

The optimum $R_{\text {smin }}$ values are much lower using ISBA-3L compared with those for ISBA-2L for the Castanet-I and -NI cases (Table 3 ). This reduction represents an improvement since the $R_{s \sin }$ values for ISBA-3L are nearly the same for the same plant species $\left(\mathrm{a} 1 \mathrm{~s} \mathrm{~m}^{-1}\right.$
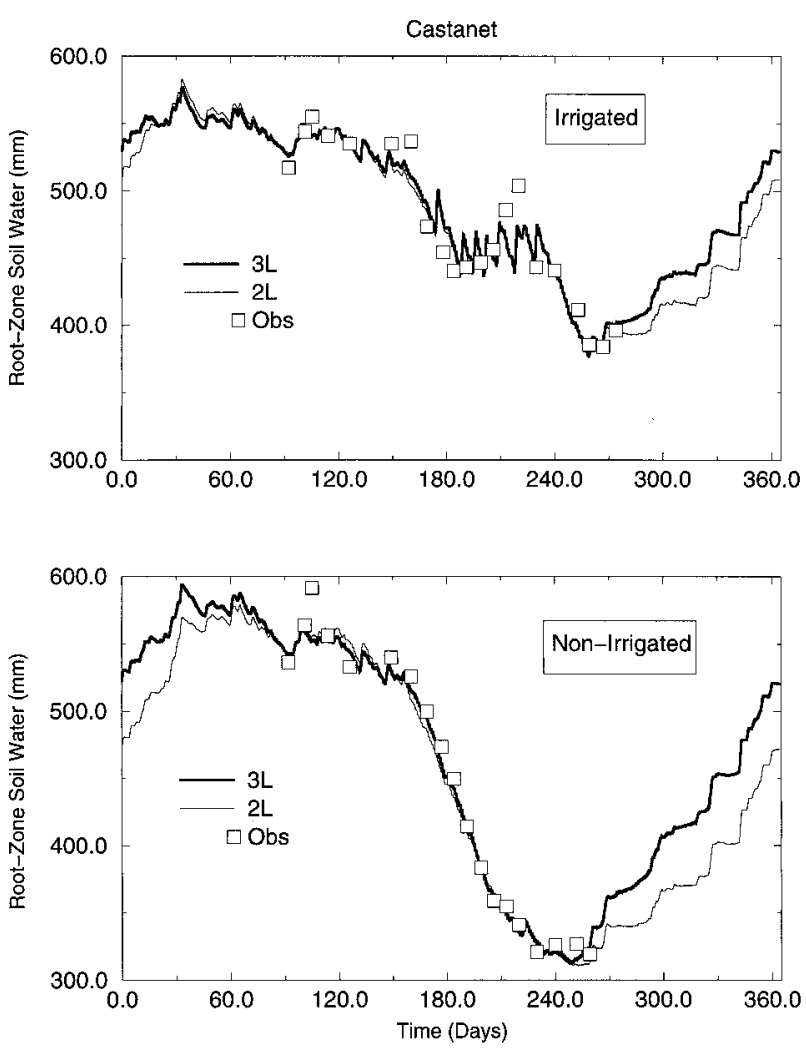

FIG. 13. The annual profile of the total soil water held within the root zone soil reservoir for the Castanet-I and -NI simulations. The thin line corresponds to the result from ISBA-2L; the thick line corresponds to ISBA-3L. Observed soil water content values are represented by the boxes.

difference) regardless of irrigation, and the magnitude of the values obtained by the optimization procedure using ISBA-3L is similar to previously reported values for corn, which were inferred from observational data: $40 \mathrm{~s} \mathrm{~m}^{-1}$ (Noilhan and Planton 1989; Jacquemin and Noilhan 1990). The $R_{s \min }$ values versus normalized rmse with respect to the soil moisture are shown in Fig. 12 for ISBA-2L and ISBA-3L for the Castanet-I and -NI cases, where the normalization factor is the available soil moisture for transpiration. The optimum $R_{\text {smin }}$ values are lower using ISBA-3L since transpiration is augmented by soil moisture diffusion from below the root zone. This effect is more pronounced for the nonirrigated case, thus resulting in a greater reduction in the optimum $R_{s \min }$ values relative to ISBA-2L.

\section{2) Annual soil moisture CyCle}

The annual cycles of the total soil water content of the root zone $\left(w_{2} d_{2}\right)$ for Castanet-I from ISBA-2L and ISBA-3L are shown in Fig. 13. Observations are indicated by the box symbols, and the thicker line represents the ISBA-3L result. Soil moisture equilibrium was obtained after cycling through the forcing for two years for ISBA-2L and five years for ISBA-3L. The only im- 
portant difference in the soil water profiles occurs in autumn; root zone soil moisture is recharged by precipitation in ISBA-2L, whereas in ISBA-3L the additional mechanism of vertical diffusion is present. This additional process results in a more rapid increase in soil water recharge, especially during October when the vertical soil moisture gradient is large and atmospheric evaporative demand has decreased. After this time period, both versions of ISBA have soil water recharge occurring at approximately the same rate and primarily caused by precipitation (since the soil moisture gradient has relaxed).

The annual cycles of the total soil water content of the root zone for Castanet-NI from ISBA-2L and ISBA$3 \mathrm{~L}$ are shown in Fig. 13. ISBA-3L produces a slightly improved soil water profile for nearly the entire growing season, which is important with respect to modeled evapotranspiration. As was the case for Castanet-I, root zone soil water recharge from mid-September through October is much more rapid for ISBA-3L. Unfortunately, no observations of soil moisture exist to validate this feature. The difference in accumulated root zone soil moisture between ISBA-2L and ISBA-3L for Castanet-NI from early September to early November amounts to approximately $40 \mathrm{~mm}$ (after this time, differences are relatively small). This amount corresponds to an average vertical diffusion of approximately 0.67 $\mathrm{mm}$ day $^{-1}$ for the time period considered.

\section{Summary}

The ISBA land surface parameterization scheme (Noilhan and Planton 1989; Noilhan and Mahfouf 1996) was modified to include a third subsurface soil moisture reservoir. The approach is based on the force-restore method (Deardorff 1977), and the root zone diffusion force-restore coefficient is parameterized as a function of soil texture and was calibrated based on the results of a multilayer soil model. Results of the three-layer scheme compared favorably with the observations of the HAPEX-MOBILHY (André et al. 1986, 1988) and INRA/Castanet (Cabelguenne et al. 1990, Calvet et al. 1998) case studies. Also, the vertical root zone soil moisture diffusion computed using ISBA-3L compared well with that computed with a multilayer soil model using the same surface physics, atmospheric forcing, parameters, and boundary conditions. Simulations that used a direct solution of the Richards equation for the same model geometry as ISBA-3L generally did not perform as well as the method that used the calibrated diffusion coefficient.

The model sensitivity to three parameters that link soil moisture to evapotranspiration was examined. When a root zone layer was added to ISBA, the best results for HAPEX-MOBILHY were obtained when the value of $w_{\text {wilt }}$ was changed from the original value used in the two-layer version of ISBA $\left(0.20 \mathrm{~m}^{3} \mathrm{~m}^{-3}\right)$ to a value $\left(0.15 \mathrm{~m}^{3} \mathrm{~m}^{-3}\right)$ which is, in fact, considered to be more representative of the HAPEX soil moisture observations (Shao and Henderson-Sellers 1996). The optimum rooting depth for ISBA $\left(d_{2}\right)$ of $1.1 \mathrm{~m}$ for HAPEX-MOBILHY was determined using the three-layer model. Overall, the annual water budget was improved by distinguishing between a root zone and a base flow layer.

The optimum plant rooting depth for Castanet-I and -NI cases studies was found to be $1.6 \mathrm{~m}$, which is reasonable for corn in this region. The optimum minimum stomatal resistance values for INRA/Castanet were nearly the same for the irrigated and nonirrigated corn crop, and the values were consistent with previously reported values. Both of these changes represent improvements relative to optimum values obtained with the two-layer version of ISBA.

The purpose of adding an additional reservoir to ISBA is to include a characterization of the root zone in the soil. This addition allows ISBA to model waterstressed conditions better and to produce greater temporal-scale separation of the surface and base flow (drainage) runoff components by defining distinct infiltration and base flow layers.

Acknowledgments. The authors are grateful to the many people who prepared the HAPEX-MOBILHY dataset and to Maurice Cableguenne who provided the INRA/Castanet datasets. Comments from three anonymous reviewers helped to improve this paper. The senior author also wishes to thank P. Bougeault for supporting this research. This work was funded by the Visiting Scientist Program at Météo-France.

\section{APPENDIX A}

\section{Soil Model Coefficients}

\section{a. Water content at the balance of gravity and capillary forces}

The surface volumetric water content at the balance of gravity and capillary forces $w_{\text {geq }}$ is defined using the CH78 soil hydraulic parameters as

$$
\frac{w_{\text {geq }}}{w_{\text {sat }}}=\frac{w_{2}}{w_{\text {sat }}}-a\left\{\left(\frac{w_{2}}{w_{\text {sat }}}\right)^{p}\left[1-\left(\frac{w_{2}}{w_{\text {sat }}}\right)^{8 p}\right]\right\},
$$

where $a$ and $p$ are empirical parameters.

\section{b. Force-restore coefficients}

The force-restore coefficients $C_{1}, C_{2}$ (Noilhan and Planton 1989), and $C_{4}$ are calibrated against multilayer soil hydrological models, and $C_{3}$ is computed analytically (Mahfouf and Noilhan 1996). The $C_{1}, C_{2}$, and $C_{3}$ force-restore coefficients are expressed as 


$$
\begin{aligned}
& C_{1}=C_{1 \mathrm{sat}}\left(\frac{w_{\mathrm{sat}}}{w_{g}}\right)^{(b / 2)+1}, \\
& C_{2}=C_{2 \mathrm{ref}}\left(\frac{w_{2}}{w_{\text {sat }}-w_{2}+w_{l}}\right),
\end{aligned}
$$

and

$$
C_{3}=\frac{\tau(2 b+2) k_{\mathrm{sat}}}{d_{3}\left[\left(w_{3}^{*} / w_{\mathrm{sat}}\right)^{-2 b-2}-1\right]},
$$

where $C_{1 \text { sat }}$ and $C_{2 \text { ref }}$ are parameters, $w_{l}$ is a small numerical value, and

$$
w_{3}^{*}=w_{\mathrm{fc}}+\frac{w_{\mathrm{sat}}+w_{\mathrm{fc}}}{e} .
$$

A formulation of $C_{1}$ that describes the vapor phase transfers for very dry soils $\left(w_{g}<w_{\text {wilt }}\right)$ is a function of surface temperature and wilting point (Braud et al. 1993; Giordani et al. 1996; Noilhan and Mahfouf 1996) from

$$
C_{1}=C_{1 \max } \exp \left(-\frac{w_{g}-w_{\max }}{2 \sigma^{2}}\right)^{2},
$$

where

$$
\begin{aligned}
C_{1 \max }= & \left(1.19 w_{\text {wilt }}-5.09\right) \times 10^{-2} T_{s} \\
& +\left(1.46 w_{\text {wilt }}+17.86\right),
\end{aligned}
$$

and

$$
\begin{aligned}
w_{\max }= & \left(-1.815 \times 10^{-2} T_{s}+6.41\right) w_{\text {wilt }}^{2} \\
& +\left(6.5 \times 10^{-3} T_{s}-1.4\right) w_{\text {wilt }} .
\end{aligned}
$$

The surface temperature is represented by $T_{s}$ expressed in Kelvins, and

$$
\sigma^{2}=-\frac{w_{\max }^{2}}{2 \ln \left(0.01 / C_{1 \max }\right)} .
$$

\section{c. Continuous formulation of soil secondary parameters}

The continuous relationships have been derived from the CH78 parameters and ISBA coefficients (Giordani 1993; Noilhan and Lacarrère 1995). Each parameter is estimated when the fractions (percentage) of sand and clay ( $X_{\text {sand }}$ and $X_{\text {clay }}$, respectively) are known.

The coefficients for the $w_{\text {geq }}$ formulation:

$$
a=732.42 \times 10^{-3} X_{\text {clay }}^{-0.539},
$$

and

$$
p=0.134 X_{\text {clay }}+3.4 \text {. }
$$

The saturated volumetric water content $\left(\mathrm{m}^{3} \mathrm{~m}^{-3}\right)$ :

$$
w_{\text {sat }}=\left(-1.08 X_{\text {sand }}+494.305\right) \times 10^{-3} .
$$

The wilting-point volumetric water content $\left(\mathrm{m}^{3} \mathrm{~m}^{-3}\right)$ :

$$
w_{\text {wilt }}=37.1342 \times 10^{-3} X_{\text {clay }}^{0.5}
$$

The volumetric water content at field capacity $\left(\mathrm{m}^{3} \mathrm{~m}^{-3}\right)$ :

$$
w_{\text {fc }}=89.0467 \times 10^{-3} X_{\text {clay }}^{0.3496} .
$$

The slope of the water retention curve:

$$
b=0.137 X_{\text {clay }}+3.501 \text {. }
$$

The value of $C_{1}$ at saturation:

$$
C_{\text {1sat }}=\left(5.58 X_{\text {clay }}+84.88\right) \times 10^{-2} .
$$

The value of $C_{2}$ for $w_{2}=w_{\text {sat }} / 2$ :

$$
C_{\text {2ref }}=13.815 X_{\text {clay }}^{-0.954} \text {. }
$$

The value of $C_{3}$ :

$$
C_{3}=5.327 X_{\text {clay }}^{-1.043} / d_{3} .
$$

\section{d. Layer-averaged soil water content at the base of the root zone}

The equation for the layer-averaged soil water content is given as

$$
\bar{w}_{2,3}=\left[w_{2}^{q}\left(d_{2} / d_{3}\right)+w_{3}^{q}\left(d_{3}-d_{2}\right) / d_{3}\right]^{1 / q},
$$

where the power $q$ is taken to be 6 . The use of a value of $q$ greater than unity is an approximation of using the so-called upstream water content. This value was determined by carrying out numerous numerical simulations and then comparing diffusion between the MLSM and ISBA-3L. As the soil moisture gradient increases, the layer-averaged water content used to evaluate the diffusion restore coefficient $\left(C_{4}\right)$ increasingly is weighted by the value of the wettest of the two subsurface soil layers from Eq. (A18). For coarse soils (i.e., $q \cong C_{4 b}$ ), $C_{4}$ resembles the layer-thickness-weighted diffusion: these soils have the largest hydraulic conductivity. For increasingly fine-textured soils, the $C_{4}$ coefficient more closely resembles diffusion as a function of the thickness-weighted water content of the layer. The use of a value of $q$ greater than unity is needed because of the coarse nature of the grid.

\section{APPENDIX B}

\section{List of Symbols}

A Surface albedo

$C_{1} \quad$ Force-restore (bare soil) soil transfer coefficient for moisture

$C_{1 \max } \quad$ Maximum $C_{1}$ value for dry soils

$C_{1 \text { sat }} \quad$ Value of $C_{1}$ at saturation

$C_{2} \quad$ Force-restore (source/sink) soil transfer coefficient for moisture

$C_{2 \text { ref }} \quad$ Value of $C_{2}$ at $w_{2}=w_{\text {sat }} / 2$

$C_{3} \quad$ Force-restore (drainage) soil transfer coefficient for moisture

$C_{4} \quad$ Force-restore (vertical diffusion) soil transfer coefficient for moisture

$C_{4 b} \quad$ Fitting parameter for vertical diffusion $\left(C_{4}\right)$ $C_{4 \text { ref }} \quad$ Fitting parameter for vertical diffusion $\left(C_{4}\right)$ 
$D_{1}, D_{2}$ Force-restore vertical diffusion terms

$E_{g} \quad$ Bare soil evaporation rate

$E_{\text {tr }} \quad$ Transpiration rate

$I \quad$ Infiltration rate

$K_{2}, K_{3}$ Force-restore drainage terms

$P_{g} \quad$ Flux of liquid water reaching the soil surface

$R_{\text {sfc }} \quad$ Surface runoff rate

$R_{\text {smin }} \quad$ Minimum stomatal resistance

$T_{s} \quad$ Surface temperature

$W_{s} \quad$ Soil water flux

$X_{\text {clay }} \quad$ Soil clay fraction

$X_{\text {sand }} \quad$ Soil sand fraction

$a, p \quad$ Coefficients for $w_{\text {geq }}$

$b \quad$ Slope of the soil water retention curve

$d_{1} \quad$ Superficial soil depth

$d_{2} \quad$ Upper-layer (root zone/infiltration) soil depth

$d_{3} \quad$ Total soil depth

$i \quad$ Soil layer

$k \quad$ Hydraulic conductivity

$k_{\mathrm{sat}} \quad$ Hydraulic conductivity at saturation

$q \quad$ Interfacial soil water interpolation factor for diffusion

$t \quad$ Time

veg Vegetation cover fraction

$w_{g} \quad$ Surface volumetric water content

$w_{\text {geq }} \quad$ Surface volumetric water content (gravity and capillary forces balance)

$w_{\mathrm{fc}} \quad$ Volumetric water content at field capacity

$w_{\text {sat }} \quad$ Volumetric water content at saturation (porosity)

$w_{\text {wilt }} \quad$ Volumetric water content at wilting point

$w_{2} \quad$ Mean volumetric water content of upper (root zone) soil layer

$w_{3}^{*} \quad$ Volumetric water content at time $t=\tau / C_{3}$

$w_{3} \quad$ Mean volumetric water content of lower (deep) soil layer

$\bar{w}_{2,3} \quad$ Interfacial volumetric water content of root zone and base flow soil layers

$z \quad$ Soil depth

$\alpha \quad$ Regression fit parameters for $C_{4 \text { ref }}$

$\beta \quad$ Regression fit parameters for $C_{4 \text { ref }}$

$\epsilon \quad$ Emissivity of the surface

$\eta \quad$ Volumetric soil water content

$\rho_{w} \quad$ Density of liquid water

$\tau \quad$ Restore constant of one day

$\psi \quad$ Soil water matric potential

$\psi_{\text {sat }} \quad$ Soil water matric potential at saturation

$\sigma \quad$ Parameter used in calculation of $C_{1}$ for dry soils

$\mathcal{D} \quad$ Richards's equation vertical diffusion coefficient

\section{REFERENCES}

Abramopoulos, F., C. Rosenzweig, and B. Choudhury, 1988: Improved ground hydrology calculations for global climate models (GCMs): Soil water movement and evapotranspiration. J. Climate, 1, 921-941.

André, J.-C., J.-P. Goutorbe, and A. Perrier, 1986: HAPEX-MOB-
ILHY: A hydrologic atmospheric experiment for the study of water budget and evaporation flux at the climatic scale. Bull. Amer. Meteor. Soc., 67, 138-144.

— results from HAPEX-MOBILHY special observing period. Ann. Geophys., 6, 477-492.

Betts, A. K., J. H. Ball, and A. C. M. Beljaars, 1993: Comparison between the land response of the ECMWF model and the FIFE1987 data. Quart. J. Roy. Meteor. Soc., 119, 975-1001.

Bonan, G. B., 1996: A land surface model (LSM version 1.0) for ecological, hydrological, and atmospheric studies: Technical description and user's guide. NCAR Tech. Note TN-417+STR, $150 \mathrm{pp}$.

Boone, A., and P. J. Wetzel, 1996: Issues related to low resolution modeling of soil moisture: Experience with the PLACE model. Global Planet. Change, 13, 161-181.

Braud, I., J. Noilhan, P. Bessemoulin, P. Mascart, R. Haverkamp, and M. Vauclin, 1993: Bareground surface heat and water exchanges under dry conditions: Observations and parameterization. Bound.-Layer Meteor., 66, 173-200.

Brooks, R. H., and A. T. Corey, 1966: Properties of porous media affecting fluid flow. J. Irrig. Drain. Amer. Soc. Civil Eng., 2, $61-88$.

Cabelguenne, M., C. A. Jones, J. R. Marty, P. T. Dyke, and J. R. Williams, 1990: Calibration and validation of EPIC for crop rotations in southern France. Agric. Syst., 33, 153-171.

Calvet, J.-C., J. Noilhan, J.-L. Roujean, P. Bessemoulin, M. Cabelguenne, A. Olioso, and J.-P. Wigneron, 1998: An interactive vegetation SVAT model tested against data from six contrasting sites. Agric. For. Meteor., 2564, 1-23.

Canadell, J., R. B. Jackson, J. R. Ehleringer, H. A. Mooney, O. E. Shala, and E.-D. Schulze, 1996: Maximum rooting depth of vegetation types at the global scale. Oecologia, 108, 583-595.

Clapp, R., and G. Hornberger, 1978: Empirical equations for some soil hydraulic properties. Water Resour. Res., 14, 601-604.

Cosby, B. J., G. M. Hornberger, R. B. Clapp, and T. R. Ginn, 1984: A statistical exploration of the relationships of soil moisture characteristics to the physical properties of soils. Water Resour. Res., 20, 682-690.

Deardorff, J. W., 1977: A parameterization of ground surface moisture content for use in atmospheric prediction models. J. Appl. Meteor., 16, 1182-1185.

Dekić, Lj., D. T. Mihailović, and B. Rajković, 1995: A study of the sensitivity of bare soil evaporation schemes to soil surface wetness, using the coupled soil moisture and surface temperature prediction model, BARESOIL. Meteor. Atmos. Phys., 55, 101112.

Delire, C., J.-C. Calvet, J. Noilhan, I. Wright, A. Manzi, and C. Nobre, 1997: Physical properties of Amazonian soils: A modeling study using the Anglo-Brazilian Amazonian Climate Observation Study data. J. Geophys. Res., 102 (25), 30 119-30 133.

Desborough, C. E., 1997: The impact of root weighting on the response of transpiration to moisture stress in a land surface scheme. Mon. Wea. Rev., 125, 1920-1930.

_ , and A. J. Pitman, 1998: The BASE land surface model. Global Planet. Change, 19, 3-18.

Dickinson, R. E., 1984: Modeling evapotranspiration for three-dimensional global climate models. Climate Processes and Climate Sensitivity, Geophys. Monogr., No. 29, Amer. Geophys. Union.

— - A. Henderson-Sellers, and P. J. Kennedy, 1993: BiosphereAtmosphere Transfer Scheme (BATS) version 1e as coupled to the NCAR Community Climate Model. NCAR Tech. Note TN$387+$ STR, $72 \mathrm{pp}$.

Dirmeyer, P. A., 1997: The Global Soil Wetness Project. GEWEX News, 7, 3-6.

Douville, H., 1997: Validation and sensitivity of the global hydrologic budget in stand-alone simulations with the ISBA land-surface scheme. Note Trav. 55, GMGEC/Météo-France, $52 \mathrm{pp}$.

_ J.-F. Royer, and J.-F. Mahfouf, 1995: A new snow parameter- 
ization for the Météo-France climate model. Climate Dyn., 12 21-35.

Dumenil, H., and E. Todoni, 1992: A rainfall-runoff scheme for use in the Hamburg climate model. Adv. Theor. Hydrol., 9, 129157.

Entekhabi, D., and P. S. Eagleson, 1989: Land surface hydrology parameterization for atmospheric general circulation models including subgrid scale spatial heterogeneity. J. Climate, 2, 816831.

Giard, D., and E. Bazile, 2000: Implementation of a new assimilation scheme for soil and surface variables in a global NWP model. Mon. Wea. Rev., in press.

Giordani, H., 1993: Description du codage du schema de surface NP89 aux normes ARPEGE: Premieres validations. Note Trav. 15, GMME/Météo-France, $62 \mathrm{pp}$.

— J J. Noilhan, P. Lacarrère, and P. Bessemoulin, 1996: Modeling the surface processes and the atmospheric boundary layer for semi-arid conditions. Agric. For. Meteor., 80, 263-287.

Goutorbe, J.-P., 1991: A critical assessment of the SAMER network accuracy. Land Surface Evaporation: Measurement and Parameterization., T. J. Schugge and J.-C. André, Eds., Springer-Verlag, 171-182.

— J J. Noilhan, C. Valancogne, and R. H. Cuenca, 1989: Soil moisture variations during HAPEX-MOBILHY. Ann. Geophys., 7, 415-426.

Habets, F., and J. Noilhan, 1997: Resultats des simulations d'ISBA dans la phase PILPS2c: Bilan hydrique du bassin de l'Arkansas (ISBA PILPS phase 2c simulation results: Hydrological budget of the Arkansas basin). Note Trav. 50, GMME/Météo-France, $59 \mathrm{pp}$.

Henderson-Sellers, A., Z.-L. Yang, and R. E. Dickinson, 1993: The Project for Intercomparison of Land-surface Parameterization Schemes. Bull. Amer. Meteor. Soc., 74, 1335-1349.

Hillel, D., 1971: Soil and Water. Academic Press.

Irannejad, P., and Y. Shao, 1996: The atmosphere-land surface interaction scheme (ALSIS): Description and validation. CANCES TR96-2, $25 \mathrm{pp}$

Jacquemin, B., and J. Noilhan, 1990: Sensitivity study and validation of a land surface parameterization using the HAPEX-MOBILHY data set. Bound.-Layer Meteor., 52, 93-134.

Kabat, P., R. W. A. Hutjes, and R. A. Feddes, 1997: The scaling characteristics of soil parameters: From plot scale heterogeneity to subgrid parameterization. J. Hydrol., 190, 363-396.

Koster, R. D., and M. J. Suarez, 1996: Energy and water balance calculations in the Mosaic LSM. Technical Report Series on Global Modeling and Data Assimilation. NASA Tech. Memo. 104606, Vol. 9, 58 pp.

Liang, X., E. Wood, and D. Lettenmaier, 1996: Surface soil moisture parameterization of the VIC-2L model: Evaluation and modification. Global Planet. Change, 13, 195-206.

Mahfouf, J.-F., and J. Noilhan, 1996: Inclusion of gravitational drainage in a land surface scheme based on the force-restore method. J. Appl. Meteor., 35, 987-992.
— - and Coauthors, 1996: Analysis of transpiration results from the RICE and PILPS workshop. Global Planet. Change, 13, 73-88.

Mahrt, L., and H. Pan, 1984: A two-layer model of soil hydrology. Bound.-Layer Meteor., 29, 1-20.

Mihailovic, D. T., 1996: Description of a land-air parameterization scheme (LAPS). Global Planet. Change, 13, 207-215.

Niyogi, D. S., and S. Raman, 1997: Comparison of four different resistance schemes using FIFE observations. J. Appl. Meteor., 36, 903-917.

Noilhan, J., and S. Planton, 1989: A simple parameterization of land surface processes for meteorological models. Mon. Wea. Rev., 117, 536-549.

— soscale modeling. J. Climate, 8, 206-223.

— zation scheme. Global Planet. Change, 13, 145-159.

Sellers, P. J., Y. Mintz, Y. C. Sud, and A. Dalcher, 1986: A simple biosphere model $(\mathrm{SiB})$ for use within general circulation models. J. Atmos. Sci., 43, 505-531.

Shao, Y., and A. Henderson-Sellers, 1996: Validation of soil moisture simulation in landsurface parameterisation schemes with HAPEX data. Global Planet. Change, 13, 11-46.

— RICE and PILPS workshop. Tech. Rep. GEWEX, PILPS, Climatic Impact Centre, IGPO Publ. 14, 179 pp.

Stamm, J. F., E. F. Wood, and D. P. Lettenmaier, 1994: Sensitivity of a GCM simulation of global climate to the representation of land-surface hydrology. J. Climate, 7, 1218-1239.

Verseghy, D. L., 1991: CLASS-A Canadian land surface scheme for GCMs. I. Soil model. Int. J. Climatol., 11, 111-133.

Viterbo, P., and A. C. M. Beljaars, 1995: An improved land surface parameterization scheme in the ECMWF model and its validation. J. Climate, 8, 2716-2748.

Wetzel, P. J., and J. T. Chang, 1987: Concerning the relationship between evapotranspiration and soil moisture. J. Climate Appl. Meteor., 26, 18-27.

- and - 1988: Evapotranspiration from nonuniform surfaces: A first approach for short-term numerical weather prediction, evapotranspiration, and soil moisture. Mon. Wea. Rev., 116, 600621.

- , and A. Boone, 1995: A Parameterization for Land-CloudAtmosphere Exchange (PLACE): Documentation and testing of a detailed process model of the partly cloudy boundary layer over heterogeneous land. J. Climate, 8, 1810-1837.

Wood, E., D. Lettenmaier, and V. Zartarian, 1992: A land-surface hydrology parameterization with subgrid variability for general circulation models. J. Geophys. Res., 97, 2717-2728.

Xue, Y., F. Zeng, and C. A. Schlosser, 1996: SSiB and its sensitivity to soil properties-A case study using HAPEX-MOBILHY data. Global Planet. Change, 13, 183-194.

Yang, Z.-L., A. J. Pitman, B. McAvaney, and A. Henderson-Sellers, 1995: The impact of implementing the Bare Essentials of Surface Transfer land surface scheme into the BMRC GCM. Climate Dyn., 11, 299-306. 